\title{
Dispersion Coefficients for Coastal Regions
}

Prepared by B. L. MacRae, R. J. Kaleel, D. L. Shearer/TRC

TRC Environmental Consultants, Inc.

Pacific Northwest Laboratory

Operated by

Battelle Memorial Institute

Prepared for

U.S. Nuclear Regulatory

Commission 


\section{NOTICE}

This report was prepared as an account of work sponsored by an agency of the United States Government. Neither the United States Government nor any agency thereof, or any of their employees, makes any warranty, expressed or implied, or assumes any legal liability of re. sponsibility for any third party's use, or the results of such use, of any information, apparatus, product or process disclosed in this report, or represents that its use by such third party would not infringe privately owned rights.

\section{Availability of Reference Materiais Cited in NRC Publications}

Most documents cited in NRC publications will be available from one of the following sources:

1. The NRC Public Document Room, 1717 H Street, N.W. Washington, DC 20555

2. The NRC/GPO Sales Program, U.S. Nuclear Regulatory Commission, Washington, DC 20555

3. The National Technical Information Service, Springfield, VA 22161

Although the listing that follows represents the majority of documents cited in NRC publications, it is not intended to be exhaustive.

Referenced documents available for inspection and copying for a fee from the NRC Public Document Room include NRC correspondence and iriternal NRC memoranda; NRC Office of Inspection and Enforcement bulletins, circulars, information notices, inspection and investigation notices; Licensee Event Reports; vendor reports and correspondence; Commission papers; and applicant and licensee documents and correspondence.

The following documents in the NUREG series are available for purchase from the NRC/GPO Sales Program: formal NRC staff and contractor reports, NRC-sponsored conference proceedings, and NRC booklets and brochures. Also available are Regulatory Guides, NRC regulations in the Code of Federal Regulations, and Nuclear Regulatory Commission Issuances.

Documents available from the National Technical Information Service include NUREG series reports and technical reports prepared by other federal agencies and reports prepared by the Atomic Energy Commission, forerunner agency to the Nuclear Regulatory Commission.

Documents available from public and special technical libraries include all open literature items, such as books, journal and periodical articles, and transactions. Federal Register notices, federal and state legislation, and congressional reports can usually be obtained from these libraries.

Documents such as theses, dissertations, foreign reports and translations, and non-NRC conference proceedings are available for purchase trom the organization sponsoring the publication cited.

Single copies of NAC draft reports are available free upon written request to the Division of Technical Information and Document Control, U.S. Nuclear Regulatory Commission, Washington, DC 20555

Copies of industry codes and standards used in a substantive manner in the NRC regulatory process are maintained at the NRC Library, 7920 Norfolk Avenue, Bethesda, Maryland, and are available there for reference use by the public. Codes and standards are usually copyrighted and may be purchased from the originating organization or, if they are American National Standards, from the American National Standards Institute, 1430 Broadway, New York, NY 10018. 
NUREG/CR-3149

PNL-4627

RB

\section{Dispersion Coefficients for Coastal Regions}

Manuscript Completed: February 1983

Date Published: March 1983

Prepared by

B. L. MacRae, R. J. Kaleel, D. L. Shearer, TRC

TRC Environmental Consultants, Inc.

Englewood, CO 80111

Under Subcontract to

Pacific Northwest Laboratory

Richland, WA 99352

\section{Prepared for}

Division of Health, Siting and Waste Management

Office of Nuclear Regulatory Research

U.S. Nuclear Regulatory Commission

Washington, D.C. 20555

NRC FIN B2384 


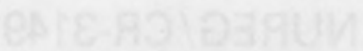

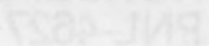

ลคำ

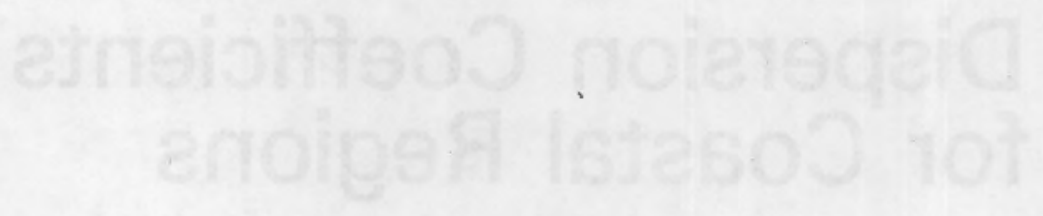

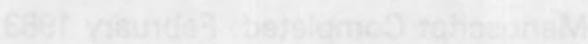

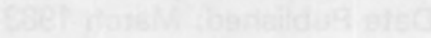

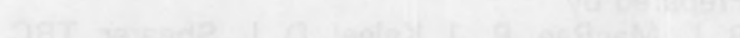

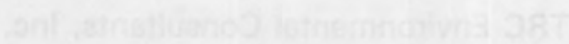

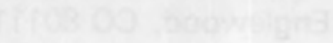

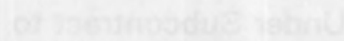

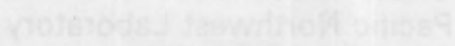

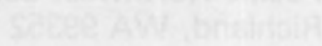

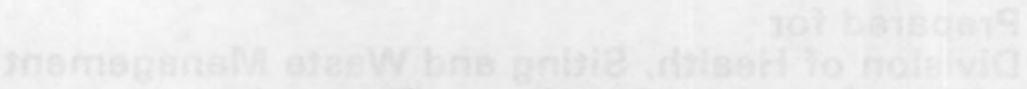

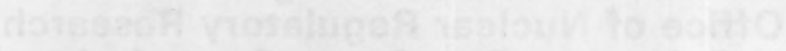

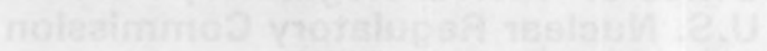

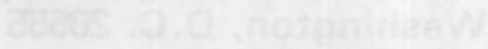

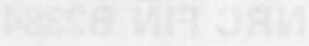


TABLE OF CONTENTS

ACKNOWLEDGMENTS.$\cdot \cdot \cdot \cdot \cdot \cdot \cdot \cdot \cdot \cdot \cdot \cdot \cdot$ v

EXECUTIVE SUMMARY ................... vii

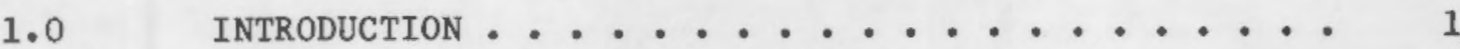

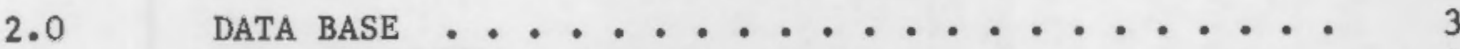

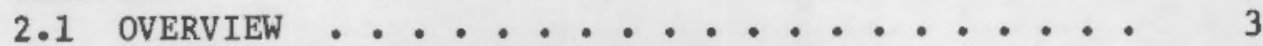

2.2 CRITERIA FOR SELECTION OF DATA SETS . . . . . 3

2.3 DESCRIPTION OF SELECTED DATA SETS ....... 4

3.0 METHODS ............................ 11

3.1 EXTRACTED DISPERSION COEFFICIENTS . . . . . 11

3.2 DERIVATION OF HORIZONTAL

3.3 DERIVATION OF VERTICAL

DISPERSION COEFFICIENTS ........ 23

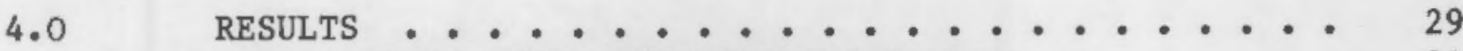

4.I COMPLEX TERRAIN/CONTINUOUS SOURCE . . . . . . 31

4.2 FLAT TERRAIN/CONTINUOUS SOURCE ........ 33

4.3 FLAT TERRAIN/INSTANTANEOUS SOURCE $. . . \cdot . \cdot 33$

4.4 ELEVATED SOURCE/PLUME DOWNWASH . . . . . . 33

4.5 SUMMARY OF RESULTS . . . . . . . . . 33

5.0 CONCLUSIONS AND RECOMMENDATIONS . . . . . . . 38

REFERENCES ........................ 40 


\section{ACKNOWLEDGMENTS}

The work reported herein was supported by Pacific Northwest Laboratory, operated by Battelle Memorlal Institute, under subcontract B-C3061-A-H. The programmatic direction and technfcal guidance of $\mathrm{Dr}$. Ronald K. Hadlock, Manager, Applied Meteorology \& Emlssion Assessment, Geosciences and Englneer1ng Department, PNL, contributed significantly to the preparation of this report. The Earth Sciences Branch, Division of Health, Siting, and Waste Management, Office of Nuclear Regulatory Research, U.S. NRC, funds PNL under FIN B2384 to conduct a program entitled "Atmospheric Dispersion Data Assessment," of which this report 1s a part. The useful and relevant perspective of $\mathrm{Dr}$. Robert F. Abbey, Jr., the NRC technical contract monttor, served to focus the effort on NRC's particular needs in the area of atmospheric transport and diffusion in shoreline environments. The contributions of Drs. Hadlock and Abbey are gratefully acknowledged. 


\section{EXECUTIVE SUMMARY}

The study being reported here was sponsored by the U.S. Nuclear Regulatory Commission (NRC). It has been directed toward obtaining and presenting atmospheric dispersion coefficients representative of coastal regions from previously conducted field measurement programs. This was done in an attempt to minimize the need to generate new data, as well as to improve the measurement programs that may still be required. In tota1, some 495 individual tracer experiments obtained from nine field measurement programs, comprised the data base. Coeffictent curves presented here have been compiled from these data to comprise a compendium of dispersion coefficients representative of coastal regions within the limits of currently available historical field measurements.

analysis:

The following conclusions are made from the results of this

- good agreement is evident between the Pasquili-Gifford coeffictent values and those derived in this study from tests performed using continuous emission sources located in flat terrain;

- results obtained from tests in complex terra1n indicate a greater degree of turbulence than those from flat terrain as the coefficient values are greater in magnitude for each stability class and downwind distance;

- instantaneous (puff) releases experience a different spectrum of turbulent eddy sizes than do continuous (plume) emission releases, as evidenced by the lower dispersion coefficients derived from experiments using instantaneous releases;

- a decrease in plume growth rates with increasing downwind distance is 1ndicated by the leveling off of many of the dispersion coefficient curves at downwind distances greater than one kilometer;

- a smaller range of coefficient values, between the most stable cases and the most unstable, is indicated by these results as compared to the Pasquill-Gifford curves.

Dispersion conditions for daylight hours and continuous emissions in a varlety of terrain conditions are well represented by the existing data set. However, there are coastal dispersion conditions likely to be 
of critical interest to the NRC that are poorly represented. Based on this; the following recommendations are made for future work on coastal dispersion:

- detailed measurements of vertical dispersion in coastal regimes should be performed;

- detailed measurements of instantaneous point source emisstons, in a variety of terraln conditions, should be performed;

- more information is needed regarding dispersion in stable atmospheres in coastal regions;

- better information on dispersion during nonsteady-state conditions, and especially conditions which are uniquely coastal in nature (such as the diurnal sea/land breeze cycle, and the turbulent internal boundary layer), should be obtalned;

- measurements of dispersion at very short (less than one k1lometer) or very long (greater than five kilometers) downwind distances should be performed;

- a standardized method of stability measurement and classifications should be employed to insure that the results from future measurment programs are easily intercomparable. 


\subsection{INTRODUCTION}

The Nuclear Regulatory Commission (NRC) has undertaken an extensive atmospheric dispersion research and measurement program from which it is intended will emerge 1mproved predictive techniques for employment in licensing decistons and for emergency planning and response. Through this program the NRC has conducted fleld measurement programs over a wide range of geographic and topographic locations, and are using the acquired tracer and meteorological measurements to evaluate existing dispersion models and prediction techniques, and to develop new techniques when necessary.

The NRC has recognized however, that extensive measurement programs have been conducted in the past by other organizations and that even though these measurements may have been designed and performed to satisfy requirements that are different from the NRC's current needs, the data may nevertheless be useful to the NRC. By 1dentifying and studying existing data bases that are sultable for their current goals, the NRC has avolded costly fleld measurement programs which essentially duplicate already existing data.

TRC Environmental Consultants, Inc. (TRC) has been contracted by the NRC, through Battelle Pacific Northwest Laboratories, to 1dentify existing data bases that will yleld adequate representations of dispersion of afrborne effluents in coastal reglons, and then to analyze selected portions of these data in such a manner as to make them suitable for the calculation of dispersion coefficlents. TRC has already conducted a review of existing information, as sumarized in a report presented to the NRC in June 1982 entitled "Critical Review of Studies on Atmospheric Dispersion in Coastal Reglons" (hereafter referred to as the Critical Review). A portion of the information isolated during the Critical Review has been evaluated in greater detall as summarized in this present report.

The purposes of this present study were threefold:

- to select data sets from which dispersion coefficlent values have been developed and sets where sufficient data were generated to enable development of dispersion coefficients characteristic of coastal reglons;

- to develop methods which enable development of coastal dispersion coefficients from existing but incomplete data sets;

- to calculate dispersion parameters and compile them with existing values to comprise a compendium on dispersion coefficients representative of coastal regions within the limits of currently avallable historical field measurements. 
The criteria used for selecting appropriate data sets is presented in Section 2.0, along with a brief description of each of the sets which comprise the data base. In Section 3.0, the methods used for calculating the dispersion parameters are presented. The results of the analysis are presented in Section 4.0, and TRC's recommendations for the application of these results, as well as for future analyses, comprise Section 5.0 . 


\subsection{OVERVIEW}

The data base employed in this study is comprised entirely of historical atmospheric tracer experimental field data collected in coastal regions and attendant meteorological measurements. The individual data sets comprising the base were collected by numerous 1nvestigators for objectives related to the study of some aspect of atmospheric processes in coastal reglons. Due to the number of studies in the past two decades and the wide range of reasons for conducting them, pertinent measurements have been made at numerous locations and under numerous field conditions.

It was determined during the Critical Review that numerous data sets do exist which could be employed to develop characteristic diffusion coefficlent values that would be specific to coastal reglons where some of the nuclear power stations are located or are planned. It was seen that some of the original investigators did develop dispersion coefficlent values while others were concerned with different objectives and thus did not determine coefficients even though they had collected approprlate data which could be employed for that purpose. The task of this study then became one of extracting values that were already developed, developing compatible values when sufficient data were avallable, then combining these coefficlent values into a compendium on dispersion coefficlents for coastal environments.

Many candidate data sets were reviewed for this study and several were selected in accordance with a set of criteria which was established based on the minimum needs for calculation of coeffictent values. Since many of the tests identified in the Critical Review were of limited scope, and therefore did not meet the criteria established for this present effort, they were excluded from extensive analysis.

\subsection{CRITERIA FOR SELECTION OF DATA SETS}

All of the studies outlined in the Critical Review were carefully reviewed to determine their applicabllity to this effort. This review was accomplished by comparing the contents of each study against specific criteria to ensure that the selected data sets were of sufficlent quality and were sufficlently complete.

Obviously, the primary criteria for selecting data sets from the available literature was the usefulness of the data toward development of dispersion prameters. Since all of the previously conducted fleld programs were designed to suit the needs of the original investigators, it is not surprising that in some cases the resulting data sets were not considered to be applicable to the objectives of this study. 
The amount of usable information that could be extracted from each measurement program was an important consideration for inclusion in this analysis. In order to derive curves of dispersion coefficients, sampling networks of more than one downwind distance are necessary. A great number of tracer tests, conducted over a wide range of atmospheric conditions, are also prerequisite for the development of dispersion coefficient curves. Studies comprised of only one downwind sampling arc, or those having a relatively small number of tracer measurements, proved to be of limited value for this study.

Another important consideration for determining the usefulness of a data set was the type of tracer material used in the measurement program. For the most part, gaseous tracers or small particle tracers (1.e., those with insignificant settling velocities) were considered to be the most appropriate. Field programs which utilized other types of tracer material, including large particles (diameters greater than 30 microns), o11-fog smoke, or tetroons, were not used in this analysis.

The final criteria used for screening the existing data sets identifled in the Critical Review was the level of effort required to make the data useful to this project. In some cases, disperston coefficients were calculated by the original investigator, making their inclusion into this analysis very straightforward. In other cases, the original investigator had tabulated the data into some form (i.e., crosswind concentration distributions) from which dispersion coeffictents could be easily derived. Finally, a group of studies remained from which the calculation of dispersion coefficlents would be quite cumbersome. Because of budgetary restraints, these studies, for the most part, could not be incorporated into this present effort.

\subsection{DESCRIPTION OF SELECTED DATA SETS}

The data sets that were selected for further analysis are summarized in Table 2.1 and their locations are depicted graphically in Figure 2.1. As discussed in the previous section, these data have been selected because they are the most applicable to NRC's objectives and they provide the most complete information currently avallable about dispersion processes in coastal zones. In total, nine data sets consisting of some 495 individual field experiments comprised the data base for the study. The nine data sets were generated between 1955 and 1976. They are Identifed as Camp Cooke (2), Millstone, San Onofre, Ocean Breeze, Dry Gulch, Mountain Iron, Shoreline, and North Norway.

The Camp Cooke diffusion trials were conducted by the U.S. Army in the area of southern California now occupied by the Vandenberg Air Force Base. The measurements, as reported by Wolfe, et a1, (1956), Cox, et a1, (1958), and Hallanger, et al, (1959), were conducted to quantify the dispersion and decay of biological warfare agents. The study utilized two types of tracer material, fluorescent particles (FP) and Bacillus Subtilles Var. Niger (BG), to simulate the dispersion and decay of 
TABLE 2.1: DETAILS OF TRACER STLDIES CHOSEN FOR ANALYSIS

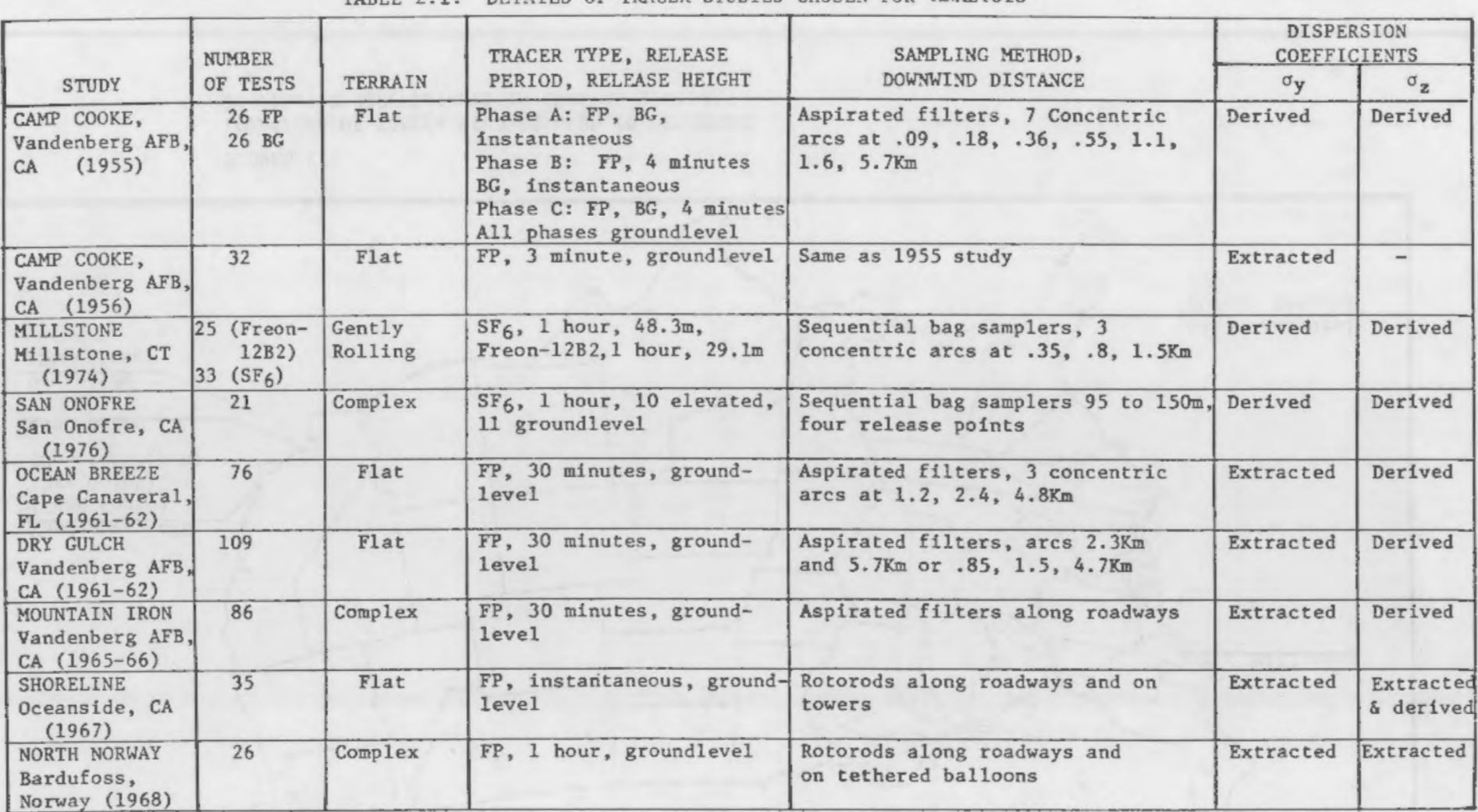

FP - Fluorescent Particles

BG - Bacillus Subtilus var. niger

$\mathrm{SF}_{6}$ - Sulfur Hexafluoride

Freon- Dibromodifluoromethane 


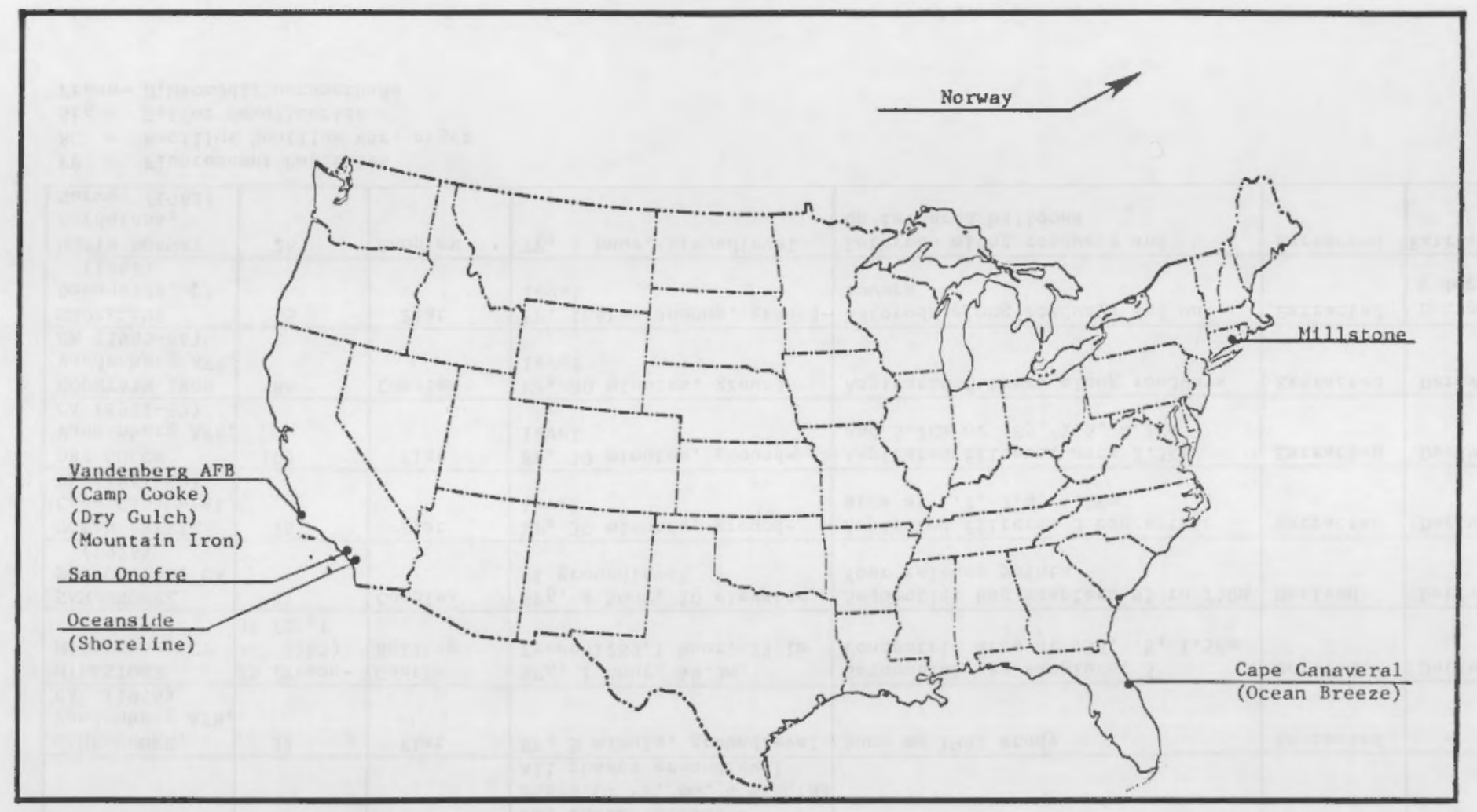

FIGURE 2,1

LOCATIONS OF TRACER STUDIES USED TO DETERMINE

DISPERSION COEFFICIENTS IN COASTAL REGIONS 
warfare agents. The 26 tracer experiments were conducted in three phases. In Phase A, bomblets containing BG and FP were detonated instantaneously. In Phase B, the FP tracer was released continuously from a Stanford generator during a four-minute period while bomblets containing BG were detonated instantaneously after half the FP was released. Durling the final phase, both tracers were released continuously over a four-minute period.

The Camp Cooke experiments were conducted shortly after sunset during the summer months in order to employ the persistent prevalling northwesterly onshore winds. Therefore, 1 t is not surprising that all of the tests were conducted during neutral or near-neutral atmospheric stability conditions. The sampling configuration consisted of concentric arcs spaced at Intervals of $0.09,0.18,0.36,0.53,1.1,1.6$, and 2.4 (or 5.7) kilometers from the point of tracer release. The BG samples were obtained using glass 1mpingers, while the FP tracer was collected using aerosol-type millipore aspirated filters.

Johnson, et al, (1975) discussed the diffusion experiments conducted at the Millstone Nuclear Power Station in Connecticut. The station is located in a partially forested, suburban area characterized by gently rolling terrain. These tests were conducted to evaluate roof-vent effluent diffusion from reactor and turbine buildings under low wind speeds. The data were originally used to develop and evaluate a site-specific diffusion model to calculate annual-average pollutant concentrations. Two different tracer materlals were used during the fleld measurement program: sulfurhexafluoride gas ( $\left.\mathrm{SF}_{6}\right)$ was released from the reactor building main vent (release helght: 44.7 meters), while Freon-12B2 gas was released from the turbine building vents (release height: 29.1 meters). The experiments were of an hours duration, but were conducted at all times of the day. Sampling of the tracer materials was accomplished using 44 sequential bag samplers located on three concentric arcs at distances of $0.35,0.8$, and 1.5 kilometers from the point of release. The samples were assayed using gas chromatography.

Another tracer program was conducted at a nuclear power station located in a coastal reglon--the San Onofre dispersion study. The San Onofre Nuclear Generating Station 1s located in southern California in an area of complex terrain. This study, as reported by Septoff, et al, (1977) was conducted to determine downwind concentrations of effluents released from the containment structure. The study $1 \mathrm{~s}$ of limited value, however, because only one sampling arc was used to measure the $\mathrm{SF}_{6}$ tracer, so dispersion coefficient curves could not be constructed. Nevertheless, the data have been included because the tests were conducted at a nuclear plant site and during periods of offshore flow--a condition that has recelved little attention to date.

The Ocean Breeze and Dry Gulch diffusion programs, as described by Haugen, et al, (1963), probably provided the most complete data available about atmospheric dispersion in coastal zones. The tests were actually 
performed in two different locations: the Ocean Breeze study was conducted at Cape Canaveral, Florida, while the Dry Gulch program was conducted at the Vandenberg Air Force Base in southern California. The primary objective of both the Ocean Breeze and Dry Gulch programs was to obtain data to be used for the development of site-specific predictive equations for determining downwind concentrations of toxic combustion by-products from rocket launches.

The 76 diffusion trials conducted during the Ocean Breeze program utilized an FP tracer released from a point source (aqueous solution in an insecticide fog applicator) for a duration of 30 minutes. The terrain at Cape Canaveral is flat, but heavily vegetated. Sampling of the tracer was accomplished using aspirated millipore filter samplers located on three nonconcentric arcs at logarithmic distances downwind. Since the tests were performed only during daylight hours, the atmospheric stability conditions that are represented by the data range from very unstable (Class A) to neutral (Class D).

The Dry Gulch study was based on the same experimental design as Ocean Breeze, except that during the Dry Gulch program two sampling arrays at the Vandenberg Air Force Base were utilized. One of the sampling arrays was established on top of a mesa, while the other was established within the Lompoc Valley. The mesa sampling array consisted of two concentric arcs at 2.3 and 5.7 kilometers from the dissemination point, and the Lompoc Valley sampling array consisted of three arcs at radial distances of $0.85,1.5$, and 4.7 kilometers from the dissemination point. The Dry Gulch program consisted of a total of 109 trials conducted during daylight hours. As with the Ocean Breeze program, only unstable and neutral atmospheric stability conditions were teated.

The Mountain Iron diffusion program, which was conducted at the southern end of the Vandenberg Aix Force Base, was performed to satisfy the same objectives as the Ocean Breeze and Dry Gulch programs--namely, to develop a predictive equation which would describe the transport and diffusion of rocket propellants and exhaust. In contrast to north Vandenberg, south Vandenberg is located in an area of complex terrain, as described by Hinds, et al, (1967, 1968) and Daubek, et al, (1969). A total of 113 tracer releases were performed during the Mountain Iron program. At least one horizontal dispersion coefficient was calculated from 86 of the tests. Fluorescent particles were released from spray nozzles at a height of 2 to 6 meters, for 15 to 30 minutes duration. Because the complexity of the terrain at south Vandenberg limited the access to downwind locations, the samplers were placed along roads, rather than in the usual concentric arcs. Tracer releases were performed during daylight hours, but the full range of atmospheric stabilities (A through $F$ as determined using the $\sigma_{\theta}$ method) were tested.

The Shoreline diffusion program, as described in the report by Smith, et al, (1969), was conducted in the summer of 1967 near Oceanside, California. The study was designed to determine diffusion 
characteristics in an area of abrupt changes in surface roughness and surface character. The tests were conducted at a flat beach which gives way to a bluff with a height of about 50 meters. Fluorescent particles were released in the form of an instantaneous puff during 35 of the tests, while afrcraft were employed for 10 additional elevated line source releases. The sampling of the FP tracer was accomplished using a total of 140 rotorod samplers which were located along roadways in a somewhat Irregular pattern to downwind distances up to 12 kilometers from the dissemination point. Sampling was also performed with vertical arrays at three locations using rotorod samplers mounted on 120 meter towers. Al1 tests were performed during near-neutral atmospheric stability conditions.

The Investigators who performed the Shoreline Diffusion Program were concerned that the tracer plume did not remain at ground level during all of the experiments. Because of the effects of surface roughness, and the compression caused by air rising over the inland bluff, the tracer plume may have become slightly elevated. To minimize any effects that might have been caused by the plume centerline being displaced above the ground, the original investigators only used the largest observed peak dosages (1.e., the measurements of plumes with the least elevations) to compute dispersion coefficlents.

The final data set selected for this analysis was obtained from field measurement programs conducted in northern Norway near Bardufoss during the summer of 1968. These tests, as described by E1dsvik, et a1, (1972) and Gotaas (1975) and summarized by Minott, et a1, (1977), were originally conducted to define dispersion characteristics in the channeled flows of deep valleys. A comparison of over-land to over-water dispersion was also presented by the authors. By design, the tests were performed in areas of complex terrain. A total of 26 tests were performed using an FP tracer. The releases were essentially from ground level, and in the form of a point source. The tracer was disseminated continuously for a duration of one hour. Rotorod samplers were used to measure downwind and crosswind dosages and vertical measurements were performed by suspending the rotorod samplers from tethered balloons.

It should be noted that some data sets identifed in the Critical Review were selected for analysis, but did not provide conclusive results. The Matagorda Deposition Trials (Ettenheim, et al, 1967) and the Victoria Diffusion Trials (Miller, 1966 and Vaughan, 1966) were conducted on the Texas Gulf coast to examine the deposition of large particles (dlameters greater than 100 microns). An effort was made to compute vertical dispersion coefficients from these data by removing the effects of particle deposition, but the results of these efforts proved to be inconclusive, and are not included in this report. The dispersion of fluorescent particles was studied by Smith, et al (1963) in a varfety of terrains. Alrcraft were employed to release the tracer as an elevated 
line source during these tests. Vertical dispersion coefficients were computed from some of these data, but again, the results were of limited value and are therefore not included here.

In summary, all of the data sets identified in the Critical Review were considered for use in this study. Although selection of useful data included those sets collected in any type of terrain, geographical area, or test dispersion condition, there remained some conditions which were not fully represented and others that were not represented at all. Notably, the main conditions that are not represented by historical data sets are the transition periods between steady-state conditions, such as the transition between the sea-breeze and the land-breeze. Since such conditions are uniquely coastal in nature, the lack of an adequate representation of them is a significant deffciency in the existing data base. Also, the existing data base does not provide as good a representation of dispersion conditions on the East and Gulf coasts, as it does of the southern California coast. This biasing of historical, coastal, and experimental data sets toward steady-state conditions in limited geographical sreas does limit the opportunity for generalization of the results of this present study. However, such information does provide an indication of where and under what conditions future work is needed. 


\subsection{METHODS}

Some of the original investigators did develop dispersion coefficient values from the data obtained during fleld measurement programs, while others, who were concerned with different objectives, did not determine coefficlents even though they had collected appropriate data that could be used for that purpose. The purpose of this study then was to extract values that were already developed, develop compatible values when sufficient data were available, then combine these coefficient values into a compendium on dispersion coefficients for coasta1 environments. This section discussses the methods used for extracting and developing the dispersion coefficient values from the data sets described in Section 2.

In order to present results from the various field measurment programs that could easily be compared, it was decided that atmospheric stability should be classified using a uniform procedure. In general, both vertical temperature profiles $(\Delta t)$ and horizontal wind direction fluctuation $\left(\sigma_{\theta}\right)$ measurements were avallable for each of the selected data sets. However, during some of the programs $\Delta t$ was measured only to a height of 10 meters, making the resultant stability class determinations highly suspect. It was decided that the $\sigma_{\theta}$ approach for classifying atmospheric stability would provide the most consistent results. The method proposed by the U.S. Nuclear Regulatory Commission office of Standards Development, entitled "The classification of Atmospheric Stability by Sigma Theta," was selected for this study. The correction recommended by the U.S. EPA (Guideline on Air Quality Models: 1980 Proposed Revision, Appendix C) was used to adjust nighttime stability classes, based on the wind speed measured at 10 meters.

\subsection{EXTRACTED DISPERSION COEFFICIENTS}

As mentioned previously, the original investigators who conducted some of the field measurement programs used the data to calculate dispersion coefficients. The application of their results to this study effort was therefore very straightforward requiring only checking the calculated values where it was possible, plotting the coefficients, and deriving the best-fit curves for each stability class.

Hinds, et al, (1967, 1968) and Daubek, et al, (1969) computed horizontal dispersion coefficienta from the data obtained during the Mountain Iron diffusion program. These results are shown in Figure 3.1. Because there were relatively few measurements performed during very unstable atmospheric conditions, the coefficients for classes $A$ and $B$ have been combined to form one curve. 0verall, the data obtalned during the Mountain Iron program yield a good representation of coastal dispersion in areas of complex terrain as a full range of atmospheric conditions were sampled. 


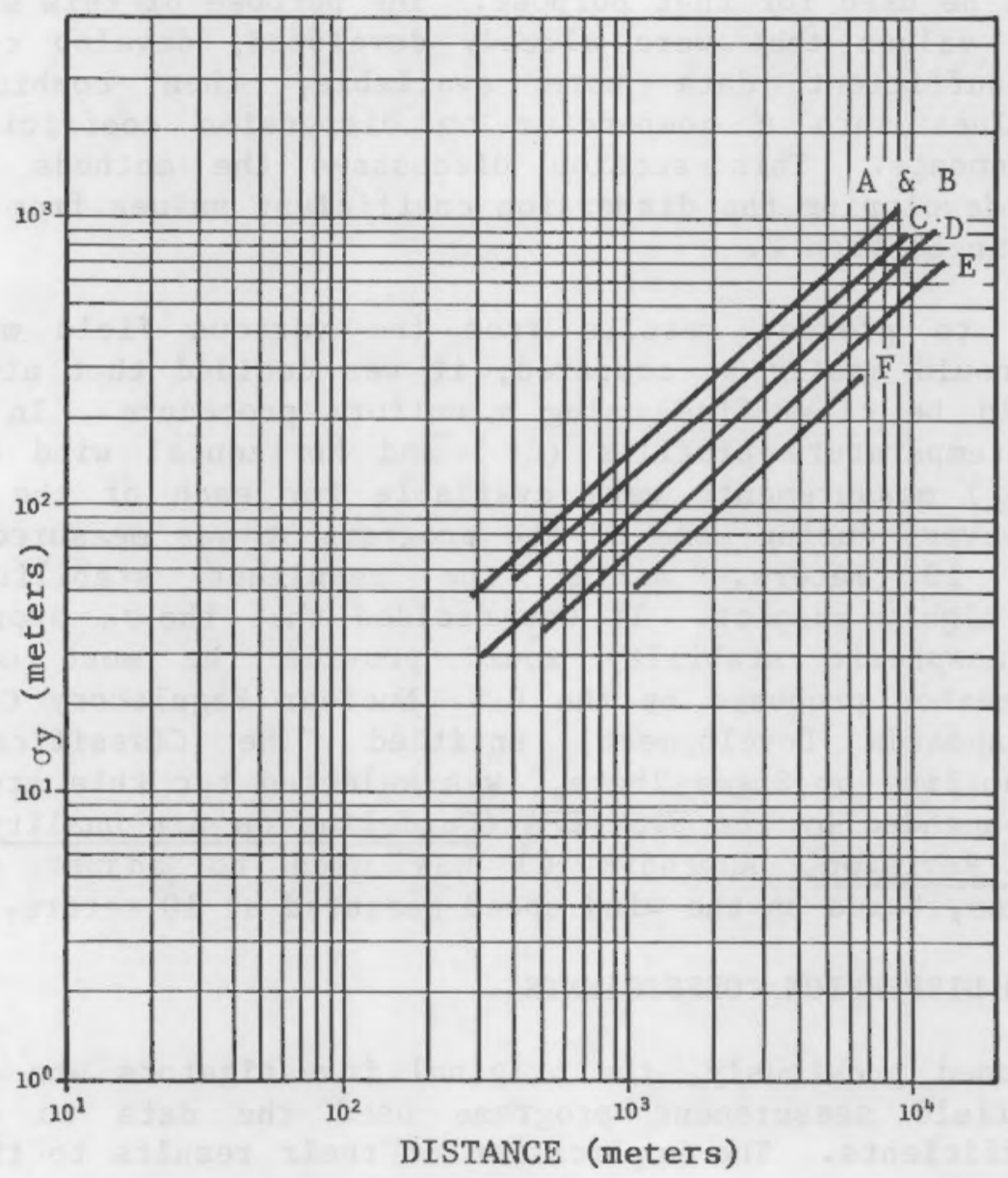

FIGURE 3.1

HORIZONTAL DISPERSION COEFFICIENTS, MOUNTAIN

IRON ( $\sigma_{\theta}$ STABILITY CLASSES) (AFTER HINDS, 1967) 
The results from the Dry Gulch and Ocean Breeze diffusion programs were presented by Haugen, et al, (1963). The horizontal dispersion coefficients obtained from these programs are deplcted in Figures 3.2 , 3.3, and 3.4. The coefficlent values are representative of unstable and neutral atmospheric conditions in coastal reglons where the terrain is relatively flat.

Figure 3.5 is a plot of the horizontal dispersion coefficients derived from data collected during the Shorellne diffusion study at Oceanside, California. These values were computed by Smith, et al, (1969). The diffusion tests during this program were conducted at various distances from the coastline during near-neutral atmospheric stability conditions.

Figure 3.6 shows coefficient values also derived from the Shoreline program for very short downwind distances. Best-fit lines have not been applied to these data however, because the values do not correlate with the appropriate stabllity classes. There are several possible explanations for the lack of stratification of the coefficient values for each stability class, but the most likely explanation $1 \mathrm{~s}$ the fact that the tracer releases were performed from three different locations which vary $1 \mathrm{n}$ both surface roughness and in distance from the coastline. Indeed the coefficient values do stratify well when they are plotted by release location, rather than by stability class. Nevertheless, the values have been included for the sake of completeness, and owing to the fact that few dispersion measurements "close-to-the-source" are available in current literature.

During the course of this study effort, it became apparent that very few actual measurements of vertical atmospherlc dispersion have been performed to date. Of the studies reviewed, only two field programs have been identifled where actual measurements of vertical dispersion were performed--the Norway and the Shoreline diffusion experiments. The vertical dispersion coefficients extracted from the Norway (Eidsvik, et al, 1972 and Gotaas, 1975) and the Shoreline (Smith, et a1, 1969) tests were summarized by Minott, et a1 (1977) and are presented in Figures 3.7 and 3.8 , respectively. There are obvious limitations upon the use of these data. The Norway study was conducted primarily to study deep-valley dispersion, and not coastal dispersion. However, the data are included here because one serles of tests was performed in a fjord, and is therefore indicative of expected dispersion rates in coastal areas of complex terrain. As mentioned previously, the Shoreline measurements were actually performed at three separate locations, and these locations have different surface roughness characteristics. For this reason, the computed vertical dispersion coefficient values did not correlate well wth the approprlate stability classes, so best-fit curves were not constructed from these data. 


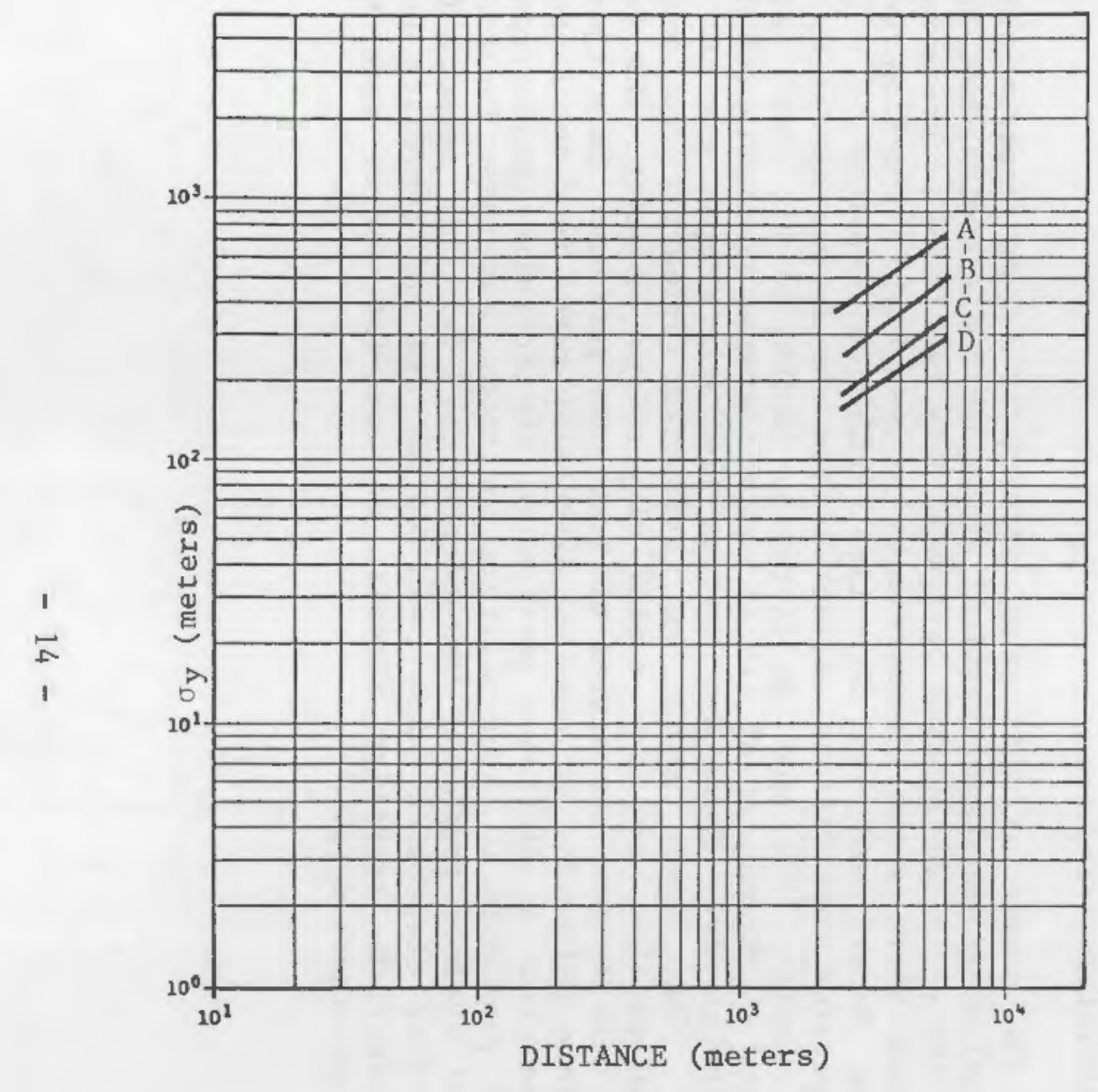

FIGURE 3.2

HORIZONTAL DISPERSION COEFFICIENTS, DRY GULCH, MESA SAMPLING ARCS, ( $\sigma_{\theta}$ STABILITY CLASSES) (AFTER HAUGEN, et al, 1963)

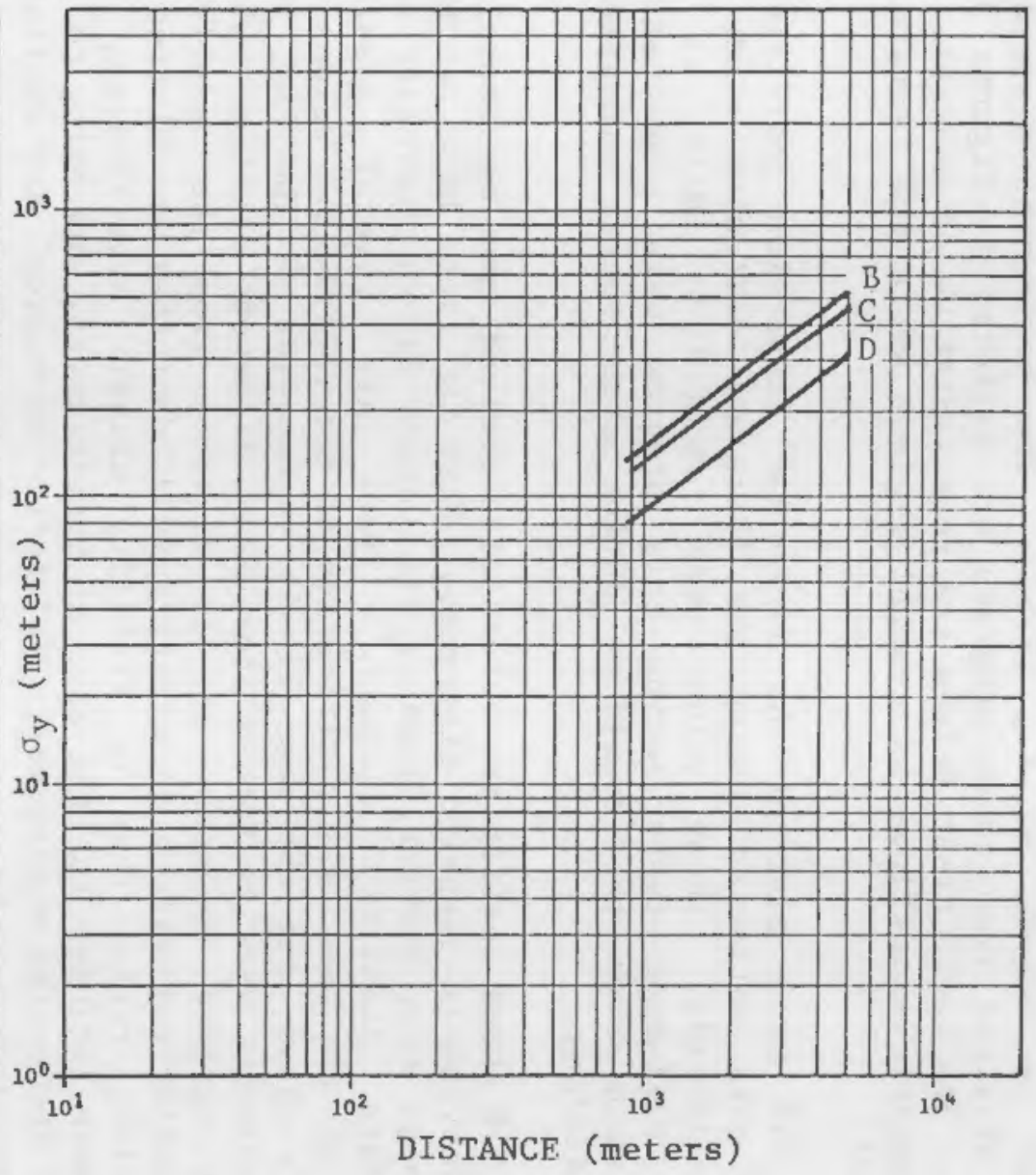

FIGURE 3.3

HORIZONTAL DISPERSION COEFFICIENTS, DRY GULCH, VALLEY SAMPLING ARCS, ( $\sigma_{\theta}$ STABILITY CLASSES) (AFTER HAUGEN, et al, 1963) 


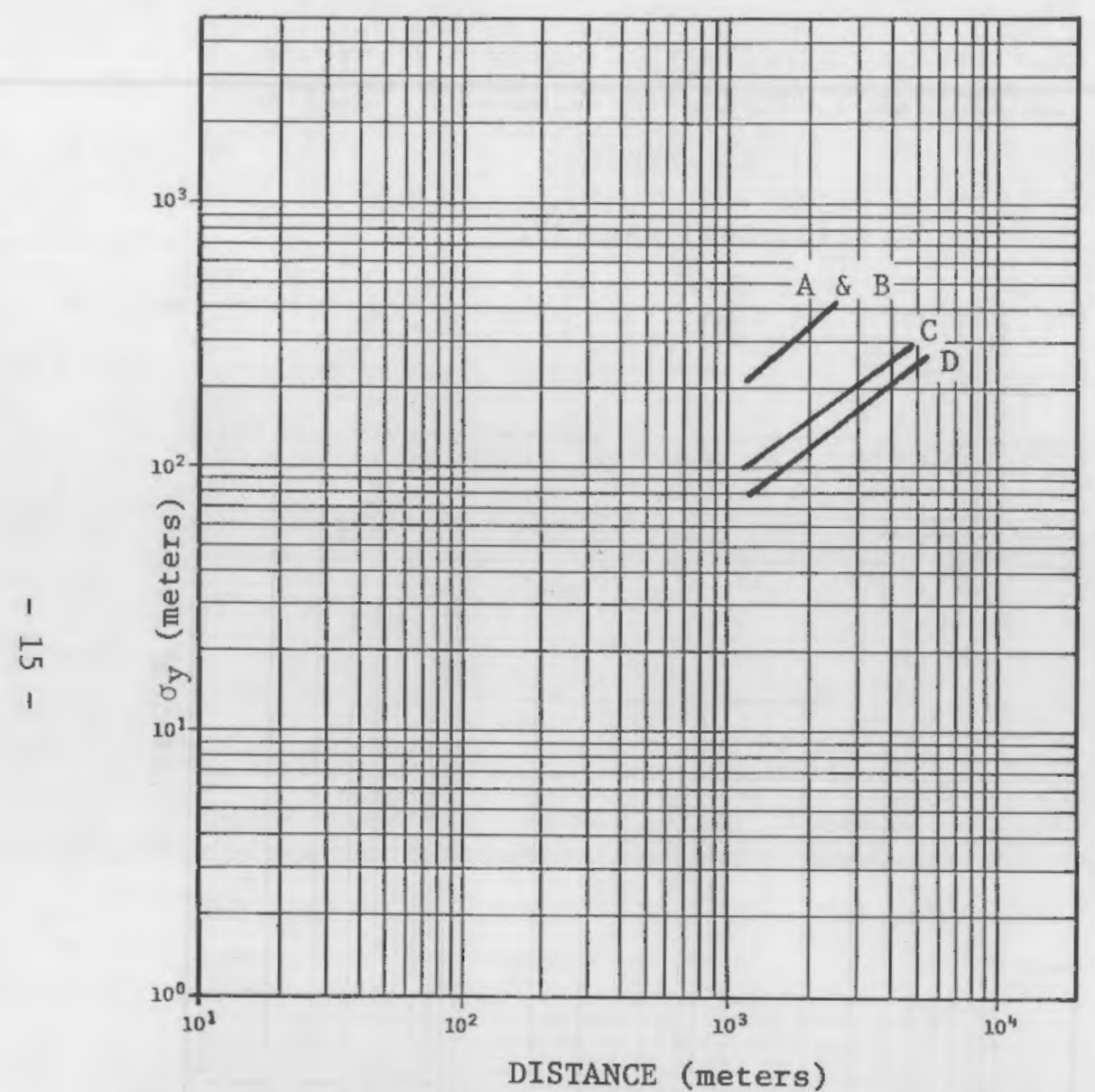

FIGURE 3.4

HORIZONTAL DISPERSION COEFFICIENTS, OCEAN BREEZE ( $\sigma \theta$ STABILITY CLASSES)(AFTER HAUGEN, et $\mathrm{a} 1,1963)$

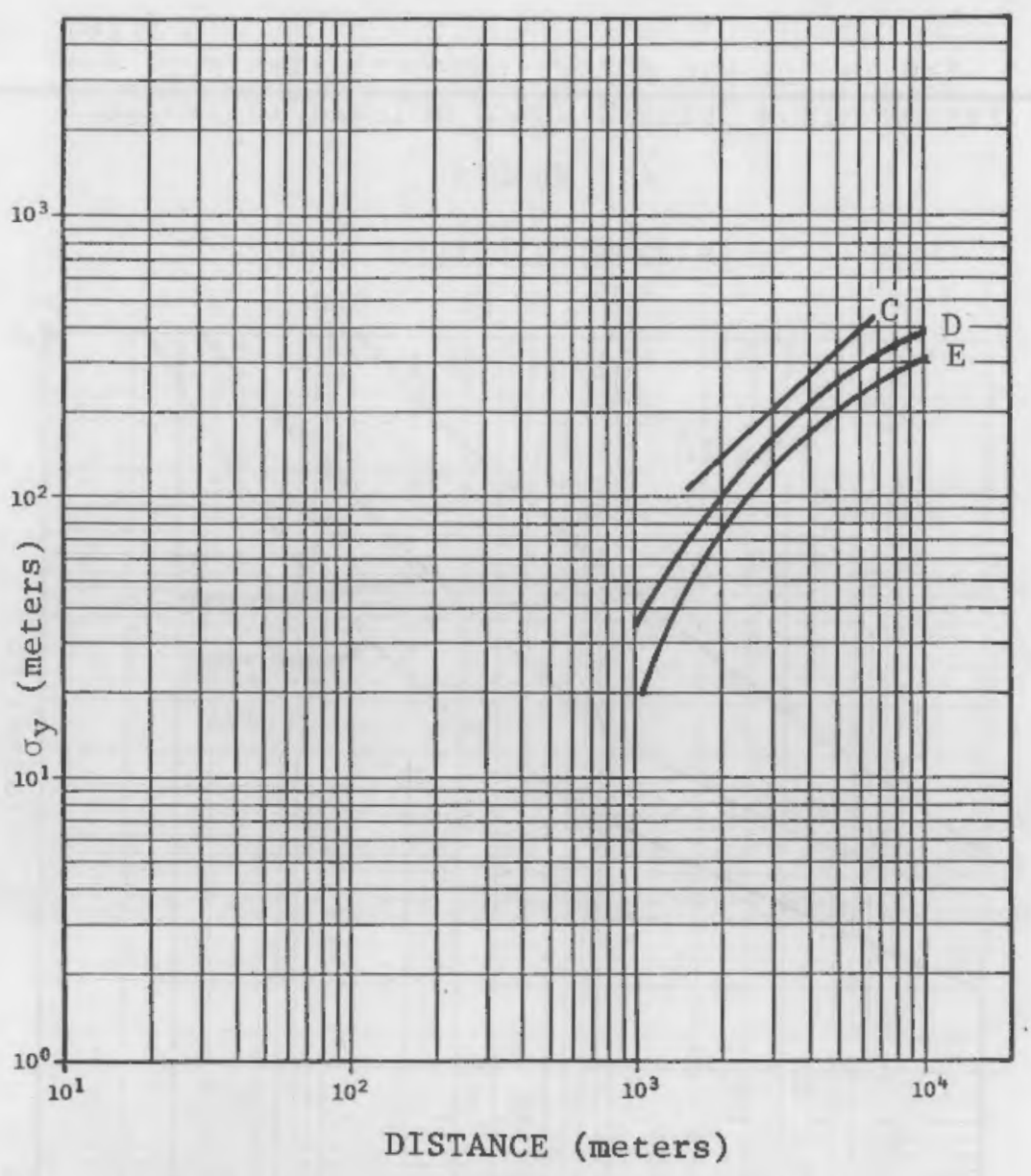

FIGURE 3.5

HORIZONTAL DISPERSION COEFFICIENTS, SHORELINE ( $\sigma_{\theta}$ STABILITY CLASSES) (AFTER SMITH, et al, 1969) 


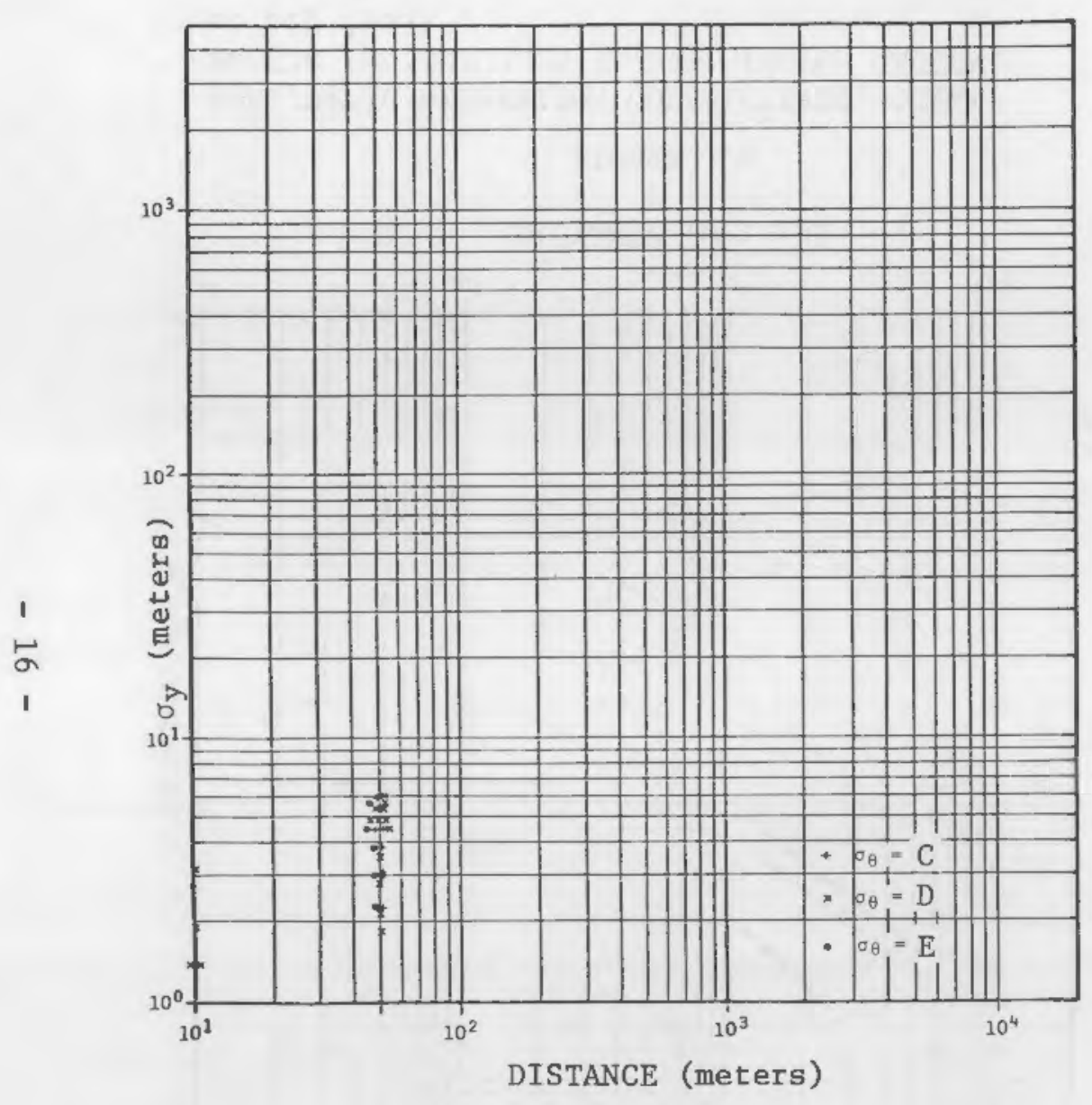

FIGURE 3.6

SHORELINE, HORIZONTAL DISPERSION COEFFICIENTS ( $\sigma_{\theta}$ STABILITY CLASSÉS) (AFTER SMITH, et al, 1969)

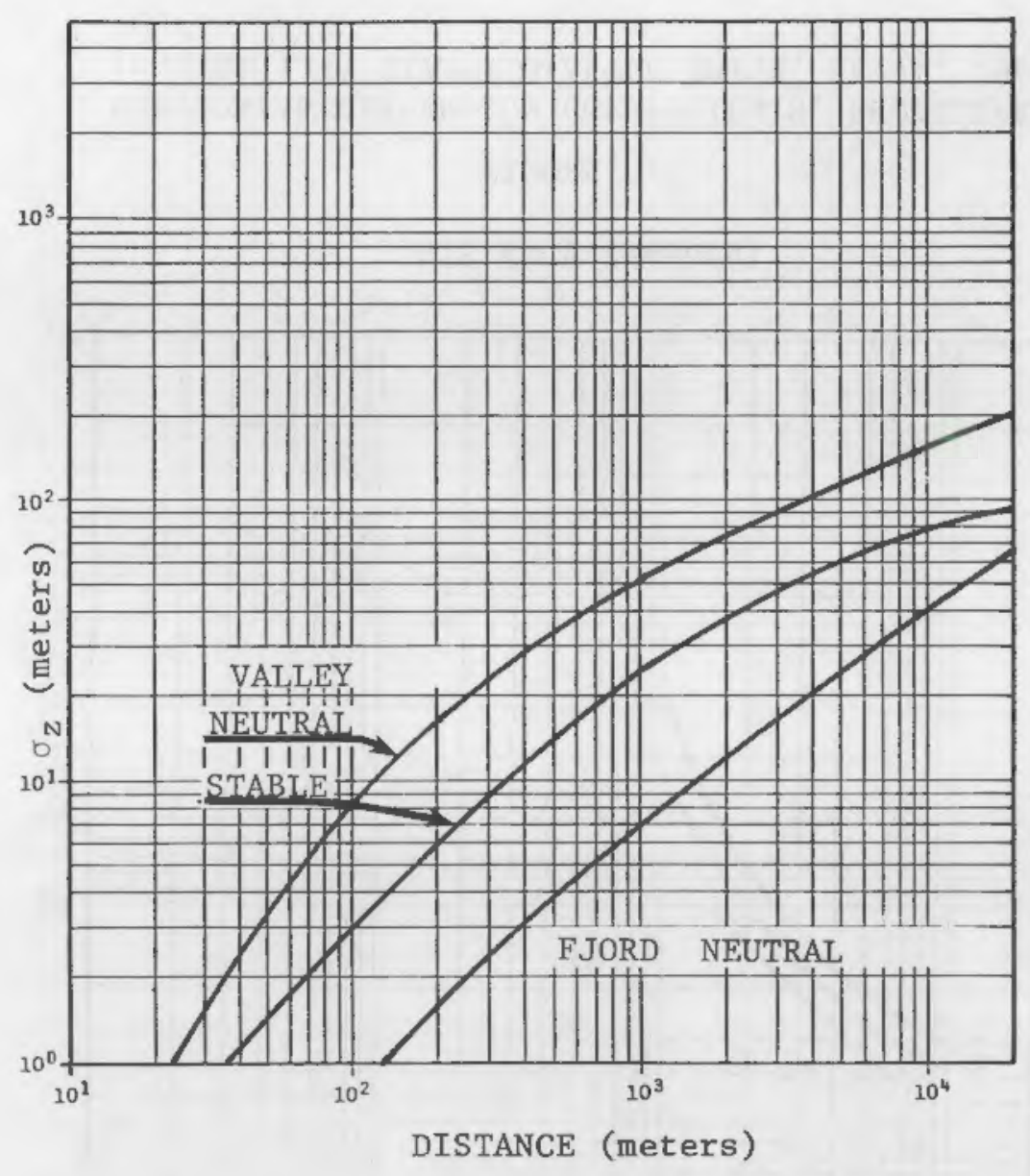

FIGURE 3.7

VERTICAL DISPERSION COEFFICIENTS, NORTH NORWAY ( $\sigma_{\theta}$ STABILITY CLASSES) (AFTER MINOTT, et al, 1977) 


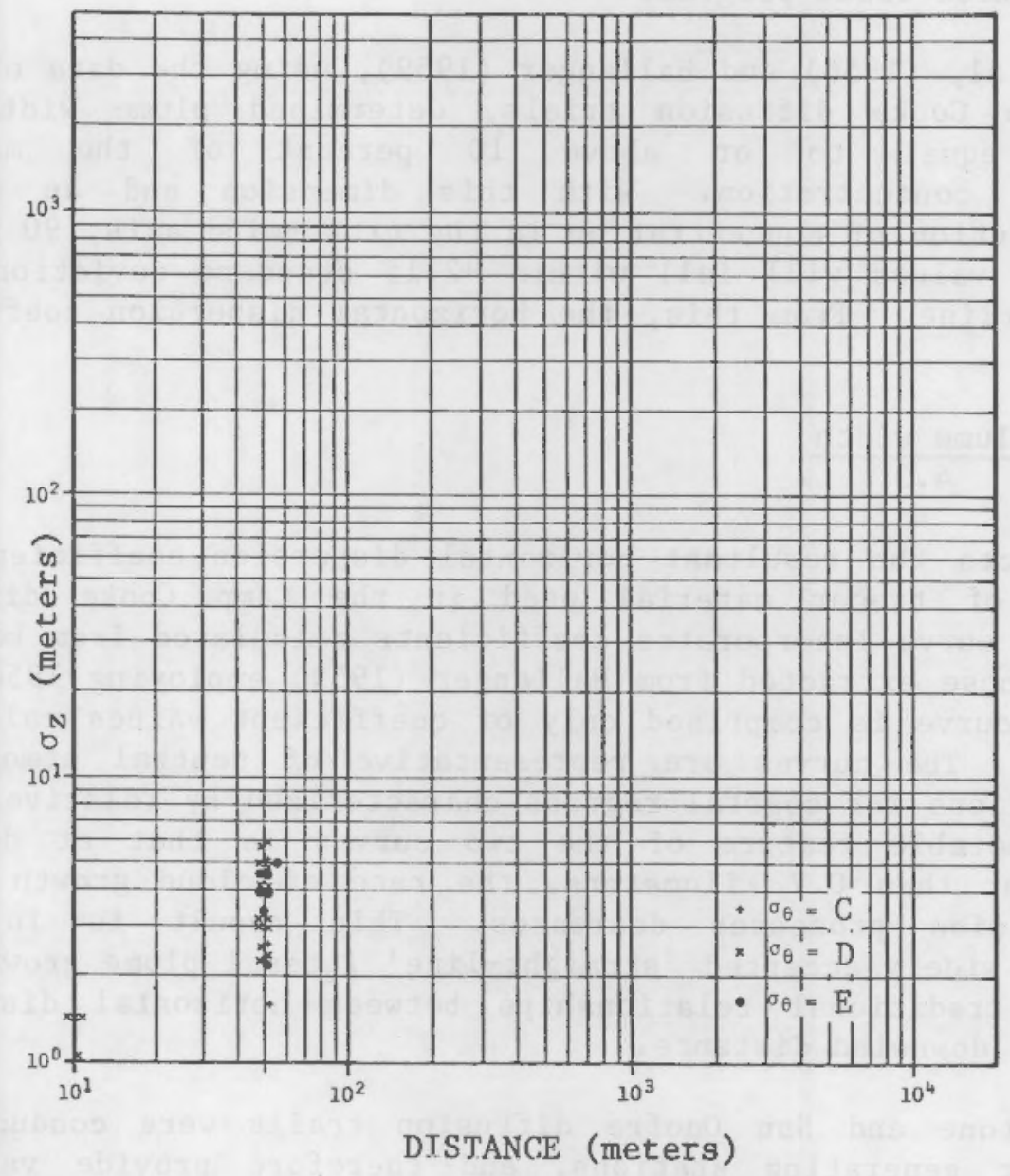

FIGURE 3.8

SHORELINE VERTICAL DISPERSION COEFFICIENTS

( $\sigma \theta$ STABILITY CLASSES) (AFTER SMITH, et a1, 1969) 


\subsection{DERIVATION OF HORIZONTAL DISPERSION COEFFICIENTS}

Some of the atmospheric tracer measurement programs were conducted to satisfy objectives other than the development of horizontal dispersion coefficients. In some cases, the original investigator tabulated the results of the diffusion trials in terms of 'plume widths' or 'crosswind concentration distributions.' Specific analytical methods were developed to allow the calculation of dispersion coefficients from the data available from these field programs.

Wolfe, et al, (1956) and Hallanger (1959), using the data obtained during the Camp Cooke diffusion trials, determined plume widths for concentrations equal to or above 10 percent of the maximum, plume-centerline concentration. With this dimension and an assumed Gaussian distribution of concentration in the cross-wind axis, 90 percent of the expected values will fall within +2.15 standard deviations from the plume centerline. From this, the horizontal dispersion coefficient is given by:

$$
\sigma_{y}=\frac{\text { plume width }}{4 \cdot 3}
$$

Figure 3.9 depicts the resultant horizontal dispersion coefficients for the two types of tracer material used in the Camp Cooke diffusion trails. The FP curve incorporates coefficients calculated from both the 1955 data and those extracted from Hallanger (1959) employing 1956 data, whereas the BG curve is comprised only of coefficient values calculated from 1955 data. The curves are representative of neutral atmospheric stability conditions for coastal reglons characterized by relatively flat terrain. One notable feature of the two curves is that at downwind distances greater than 0.7 kilometers, the rate of cloud growth due to turbulent diffusion processes decreases. This result is in sharp contrast to the widely accepted 'straight-line' lateral plume growth rate represented by traditional relationships between horizontal dispersion coefficients and downwind distance.

The Millstone and San Onofre diffusion trails were conducted at existing nuclear generating stations, and therefore provide valuable, 'real-wor1d' information that is directly applicable to the NRC's objectives. Unfortunately, the presence of the plant complex alters the wind and turbulence regime in its vicinity, thereby making the development of dispersion coefficients more difficult.

Johnson, et al, (1975) and Septoff, et al, (1977) tabulated the results of the Millstone and San Onofre diffusion trials, respectively, in the form of crosswind integrated concentrations which were converted to plume width and subsequently to horizontal dispersion coefficients using the method described previously. 


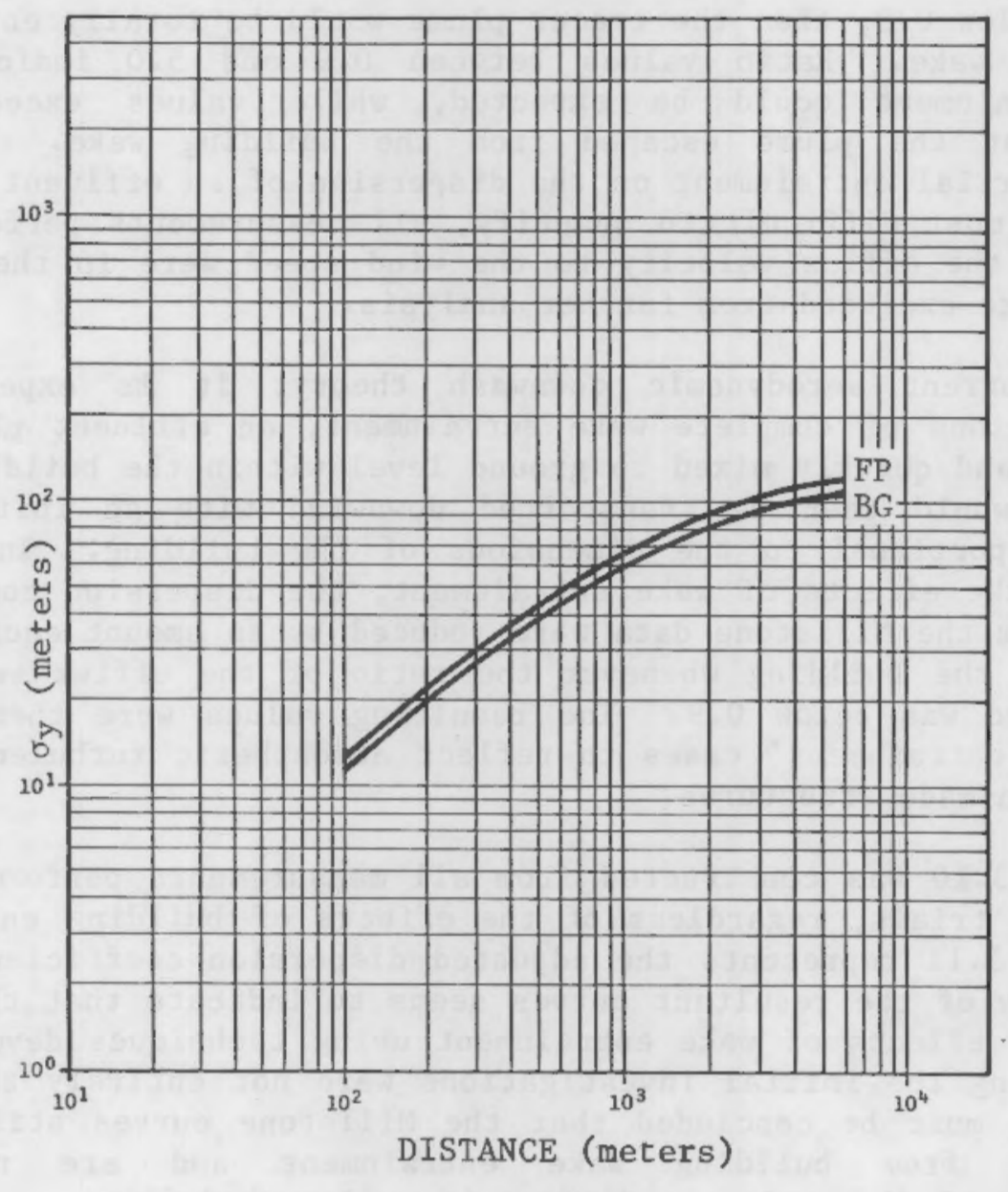

FIGURE 3.9

HORIZONTAL DISPERSION COEFFICIENTS, CAMP COOKE 
The coefficients developed from these data partially represent the increased turbulence and wake effects resulting from the air flow over and around the reactor and turbine buildings. An attempt was made to remove the effects of bullding entrainment by utilizing a scheme developed by Johnson during the Millstone diffusion trials. Visual observations of oil-fog tracer experiments conducted at the Millstone station indicated that the ratio between the tracer efflux velocity and the ambient wind speed could be used as a predictor of the occurrence of building entrainment or downwash effects. Johnson found that if the rat1o fell below 0.9 , then the tracer plume would be totally entrained in the bullding wake. Ratio values between 0.9 and 5.0 indicated that partial entrainment could be expected, while values exceeding 5.0 Indicated that the plume escaped from the building wake. Since the effects of partial entrainment on the dispersion of an effluent plume are probably the most difficult to quantify, all measurements performed when the ratio of the efflux velocity to the wind speed were in the range of 0.9 to 5.0 were excluded from further analysis.

From current aerodynamic downwash theory, it is expected that during conditions of complete wake entrainment, an effluent plume would be entrained and quickly mixed to ground level within the building's wake cavity. It would then be transported downwind with an initial plume dimension proportional to the dimensions of the bullding. In order to account for the effects of wake entrainment, the dispersion coefficients developed from the Millstone data were reduced by an amount equivalent to the width of the building whenever the ratio of the efflux velocity to the wind speed was below 0.9 . The resulting values were then combined with the 'no entrainment' cases to reflect atmospheric turbulence in the absence of man-made structures.

Figure 3.10 was constructed from all measurements performed during the Millstone trials, regardless of the effects of building entrainment, while Figure 3.11 represents the adjusted dispersion coefficient curves. The similarity of the resultant curves seems to indicate that the efforts to remove the effects of wake entrainment using techniques developed for the site during the initial investigations were not entirely successful. Therefore, it must be concluded that the Millstone curves still contain some effects from building wake entrainment and are not fully representative of dispersion conditions in undisturbed flow.

Crosswind concentrations were tabulated by Septoff, et a1, (1977) from the data collected at the San Onofre Nuclear Generating station (SONGS). Dispersion coefficients were calculated from Septoff's results by the same technique used for the Millstone data. However, the sampling configuration at SONGS consisted of only one downwind sampling arc, making these results of limited value. The dispersion coefficients calculated for this sampling arc are shown in Figure 3.12. The SONGS study seems to indicate that offshore flow and turbulence induced by the plant complex create very good dispersion at short downwind distances (100-150 meters). 


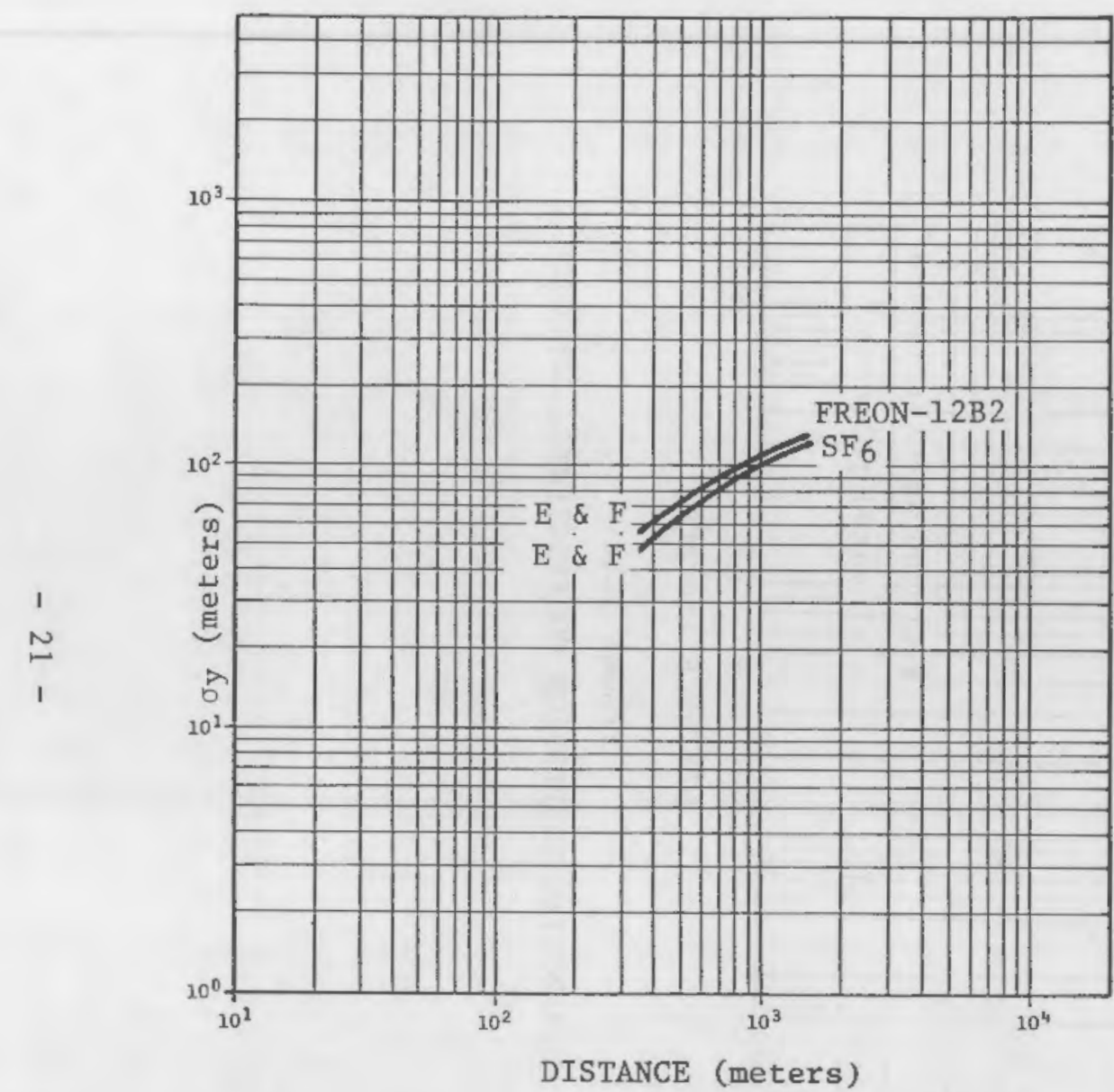

FIGURE 3.10

HORIZONTAL DISPERSION COEFFICIENTS, MILLSTONE $\left(\sigma_{\theta}\right.$ STABILITY CLASSES)

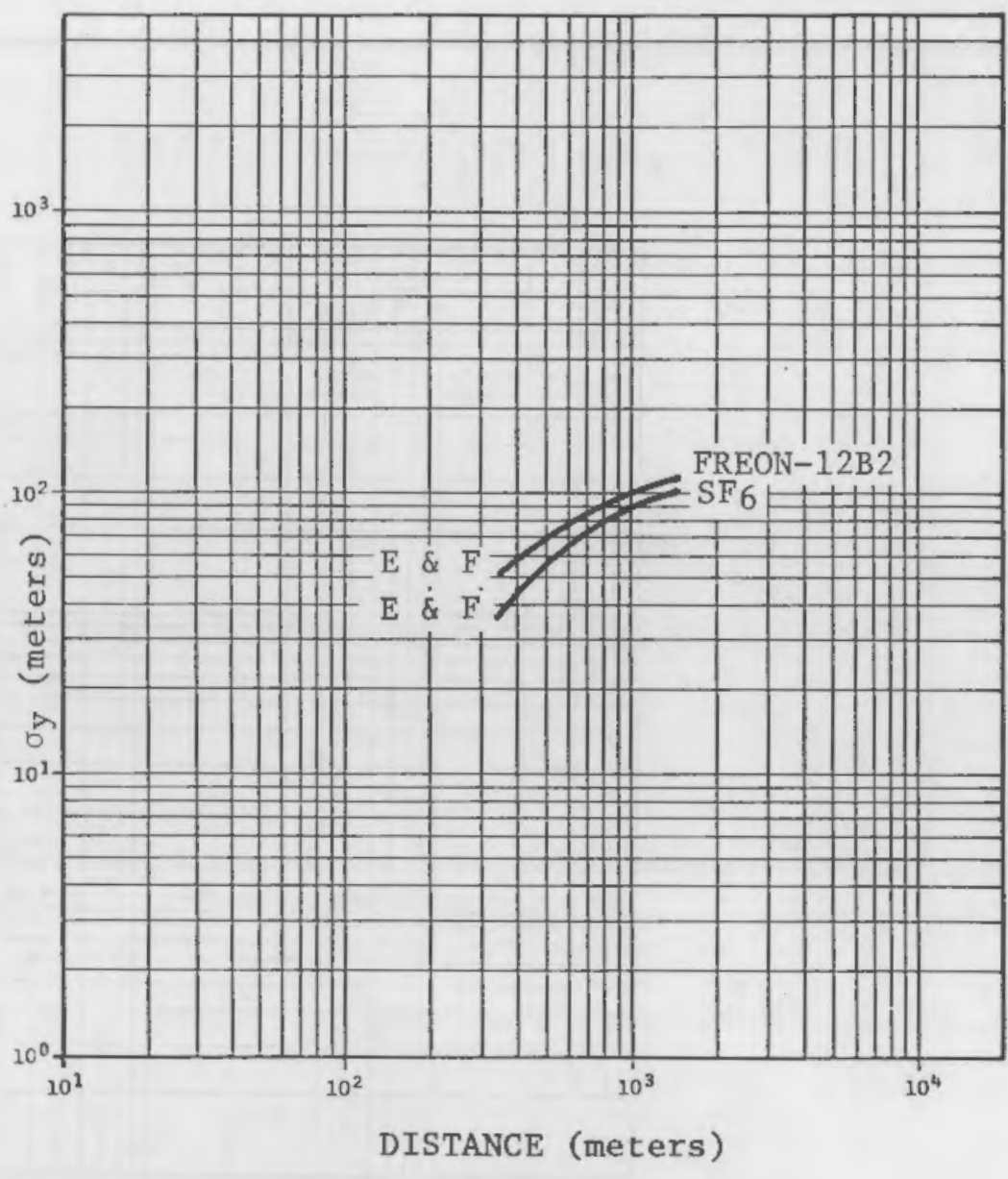

FIGURE 3.11

HORIZONTAL DISPERSION COEFFICIENTS WITH WAKE ENTRAIMMENT EFFECTS REMOVED, MILLSTONE, $\left(\sigma_{\theta}\right.$ STABILITY CLASSES) 


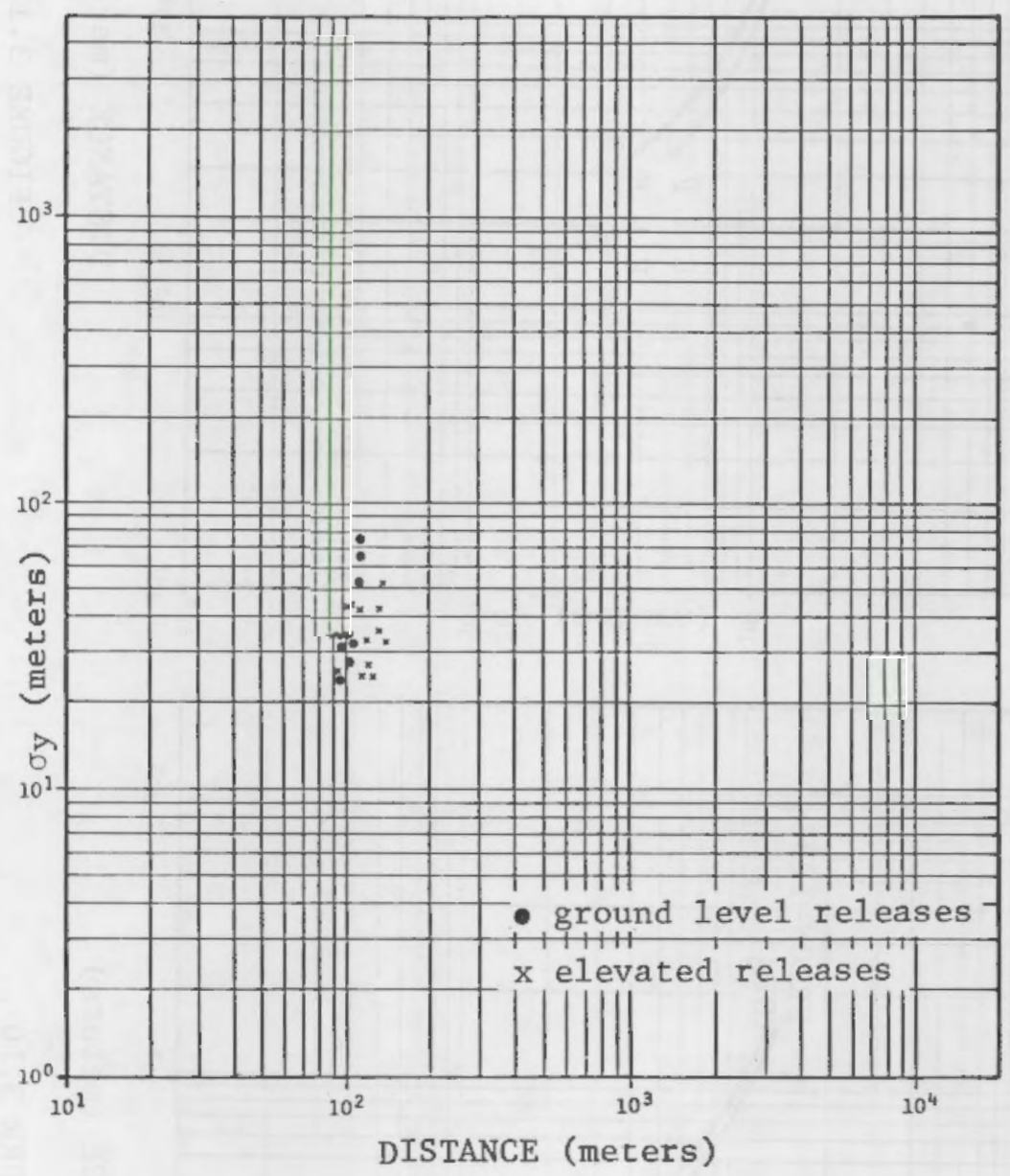

FIGURE 3.12

HORIZONTAL DISPERSION COEFFICIENTS, SAN ONOFRE 


\subsection{DERIVATION OF VERTICAL DISPERSION COEFFICIENTS}

One of the primary weaknesses of applying existing data bases derived from previously conducted tracer measurment programs to the current needs of the NRC, is the almost complete lack of measurements of atmospheric dispersion in the vertical. As mentioned previously, the Norway and the Shoreline diffusion experiments were the only tests identified where vertical measurements of atmospheric dispersion have been performed in coastal regions in enough detall for determination of dispersion coefficients. For this analysis, an attempt has been made to utilize the much more extensive coastal dispersion measurements in the horizontal direction to derive estimates of vertical dispersion coefficients by applying the relationships expressed in the Gaussian plume model. As will be discussed however, there are inherent flaws in applying the Gaussian assumption to calculate $\sigma_{z}$ in lieu of utilizing actual measurements.

Vertical dispersion coefficients $\left(\sigma_{z}\right)$ were calculated using the following form of the Gaussian plume model:

$$
\sigma_{z}=\frac{Q}{(2 \pi)^{1 / 2} x_{\text {cwid }} \bar{u}}
$$

Equation 3.1

where: $\quad \bar{u}=$ mean wind speed

$$
\begin{aligned}
X_{\text {cwid }}= & \text { crosswind integrated dosage, and } \\
Q= & \text { source strength, or In this case, } \\
& \text { the number of particles. }
\end{aligned}
$$

An equivalent form of this equation is:

$$
\sigma_{z}=\frac{Q}{2 \pi \chi_{\max } \sigma_{y} \bar{u}}
$$

Equation 3.2

where: $X_{\max }=$ maximum centerline concentration.

Equations 3.1 and 3.2 were derlved by assuming complete deposition of the tracer particles upon impaction at the ground, since this assumption most closely describes the physical processes that can be expected to occur during the field measurements. These equations have been applied to the data obtained during the Camp Cooke, Ocean Breeze, Dry Gulch, Mountain Iron, Millstone and San Onofre diffusion experiments to derive vertical dispersion coefficients that are representative of conditions in coastal regions.

Vertical dispersion coefficients derived from the Camp Cooke data are shown in Figure 3.13. The resultant curve is only representative of the neutral atmospheric conditions that were prevalent during the original tracer experiments. It should be noted that there is 


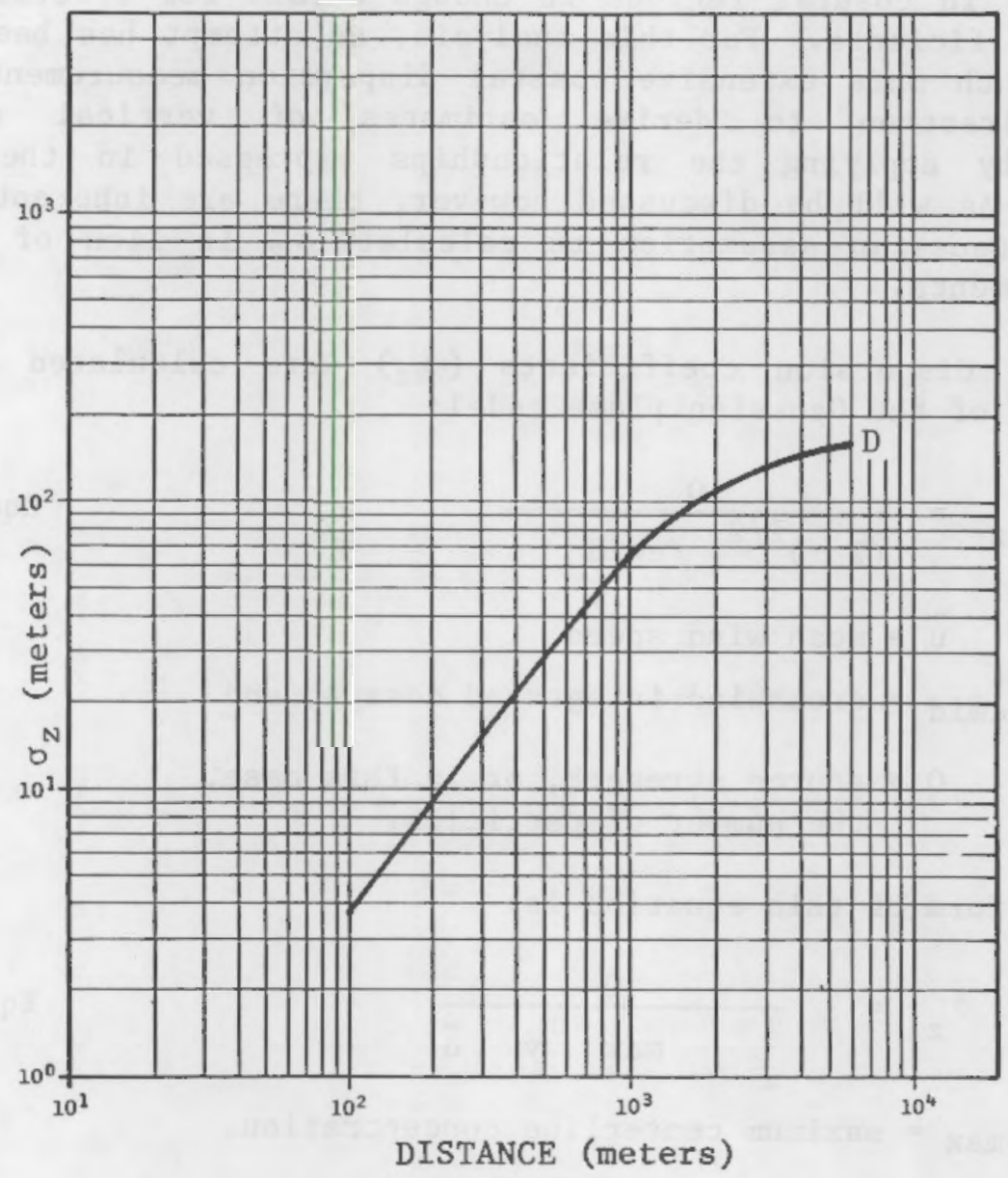

FIGURE 3.13

VERTICAL DISPERSION COEFFICIENTS, CAMP COOKE $(\sigma \theta$ STABILITY CLASS) 
uncertainty regarding the source strengths during the Camp Cooke trials, which may affect the reliability of the coefficlent estimates presented In Figure 3.13. The efficiency of the bomblets used for dissemination of the BG tracer at Camp Cooke was found to be as low as 30 percent, while the efflciency of the Stanford generator used for FP dissemination was about 80 percent (Martinez, 1965). It is probable that the emission source strengths have been overestimated for many of the Camp Cooke trlals, which will tend to cause an overestimation of $\sigma_{z}$ as well.

Figures $3.14,3.15$, and 3.16 depict the vertical dispersion coefficients derived from the Ocean Breeze, Dry Gulch, and Mountain Iron diffusion tests, respectively. These data provide a fairly good representation of dispersion over the full range of expected atmospheric stability conditions. The Ocean Breeze and Dry Gulch results are applicable to coastal regions where the terrain is predominantly flat, whereas the Mountain Iron data are more representative of more complex terrain conditions.

The effects of the added turbulence created by the presence of a bullding complex on the vertical growth of an effluent plume are represented in Figures 3.17 and 3.18 which have been derived from tracer experiments conducted at the Millstone and San Onofre Nuclear Generating Facilities, respectively. The Millstone results are depicted by two curves, both of which are representative of stable atmospheric conditions, because as previously mentioned, two different tracers were used to study the different points of effluent release within the plant complex. The turbulent structure of the atmosphere downwind of the various plant buildings is undoubtedly a contributing factor to the differences exhibited by the two tracer types because the tracers were released at different locations within the plant complex. Since the measurements at the San Onofre facility were performed at essentially one downwind distance, coefficlent curves as a function of distance could not be constructed from these data.

Direct measurements of vertical dispersion were not performed during any of the tracer experiments mentioned in this section, so the accuracy of the calculated coefficient values could not be assessed. Since the mathematical technique used in this study depends on a precise knowledge of several parameters, such as the emlssion source strength, the downwind maximum centerline concentration, the crosswind concentration distribution, and the mean wind speed, any inaccuracies in the measurement of these input variables will be reflected in the resulting vertical dispersion coefficients. Indeed, the application of the Gaussian assumption itself may not be appropriate in all cases. The need for actual measurements of vertical dispersion in coastal regions cannot be overemphasized. 


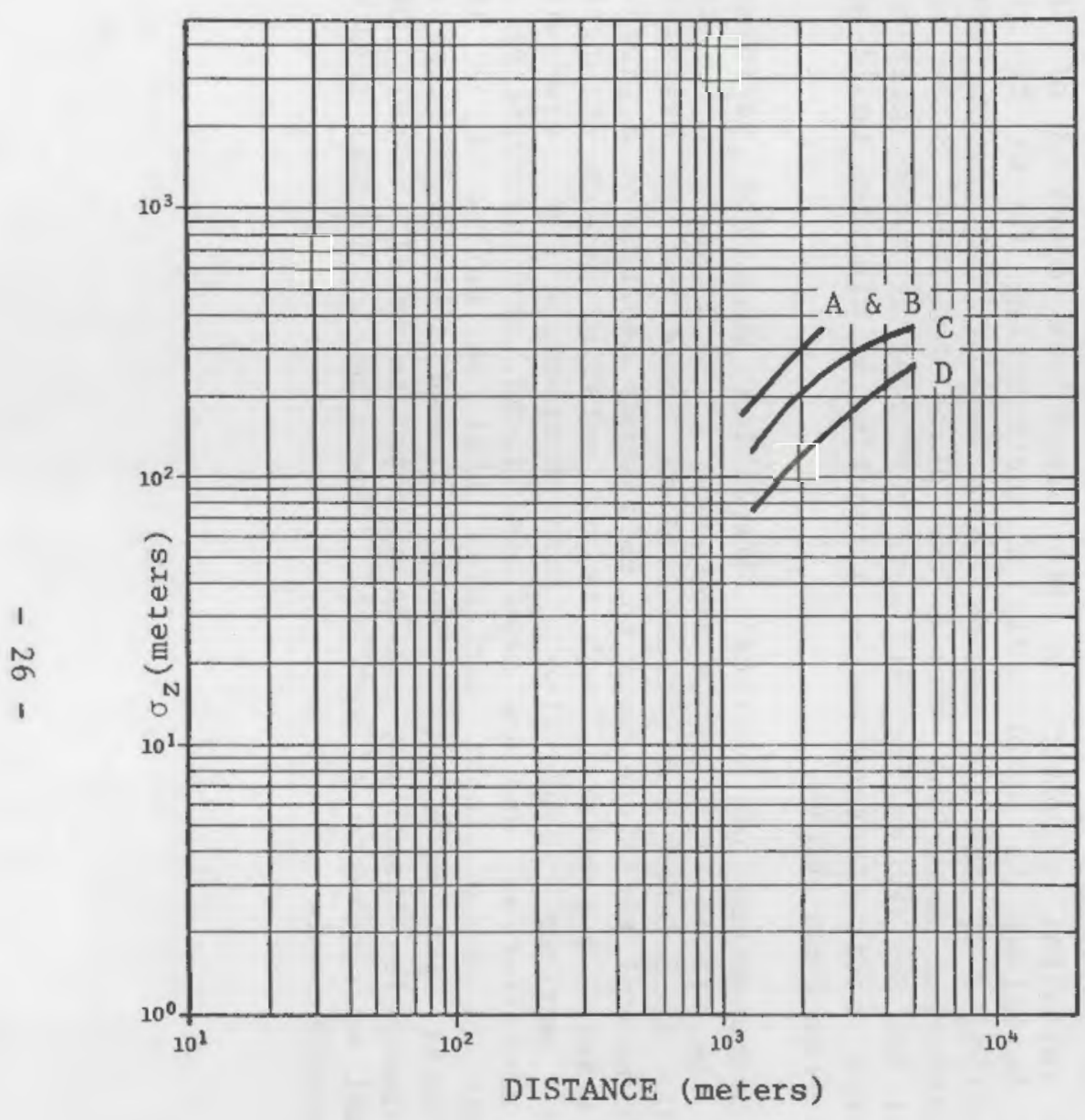

FIGURE 3.14

VERTICAL DISPERSION COEFFICIENTS, OCEAN BREEZE $\left(\sigma_{\theta}\right.$ STABILITY CLASSES) (AFTER HAUGEN, et al, 1963)

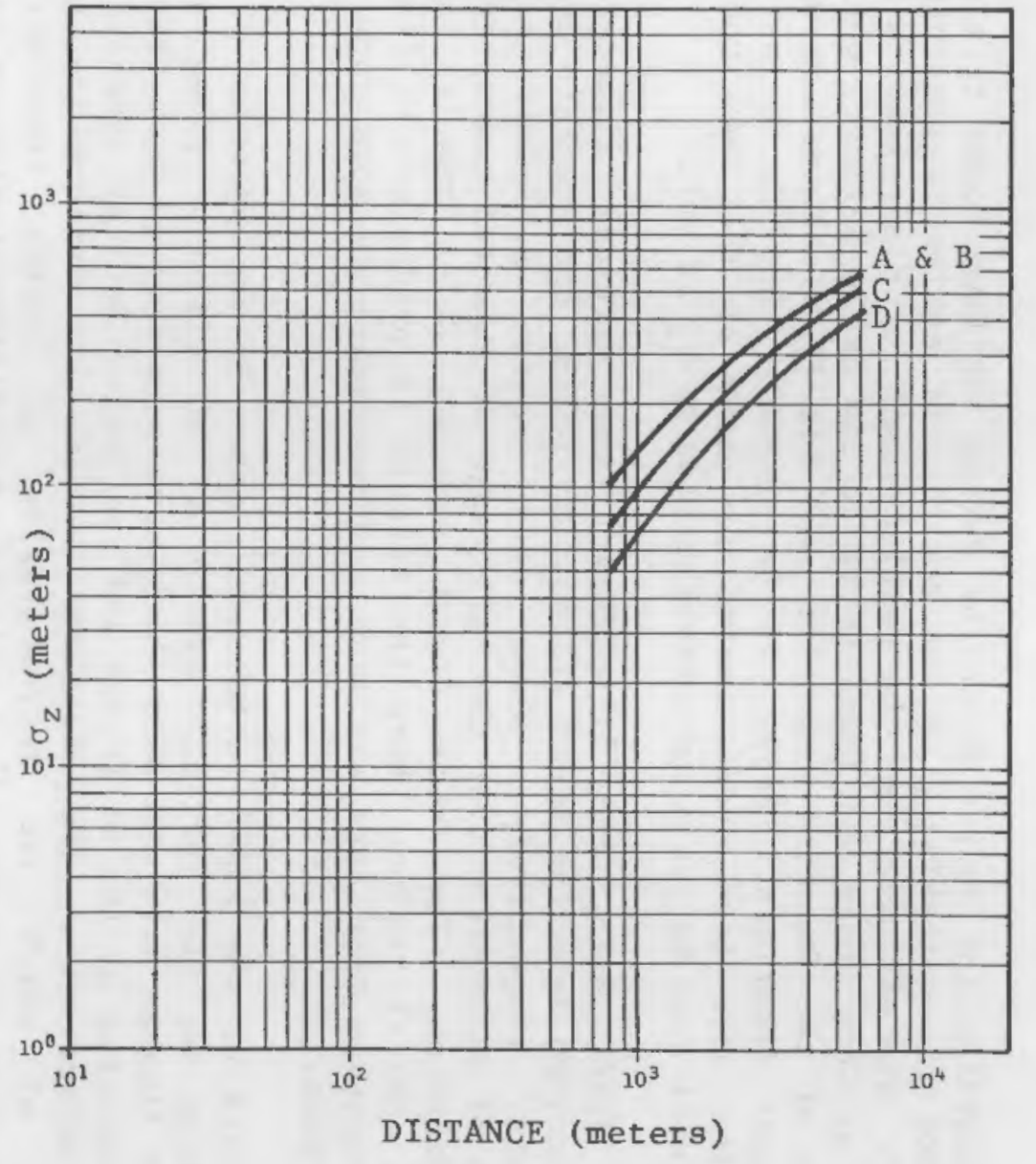

FIGURE 3.15

VERTICAL DISPERSION COEFFICIENTS, DRY GULCH, AVERAGE OF VALLEY AND MESA SAMPLING ARCS, $(\sigma \theta$ STABILITY CLASSES)(AFTER HAUGEN, et al, 1963) 


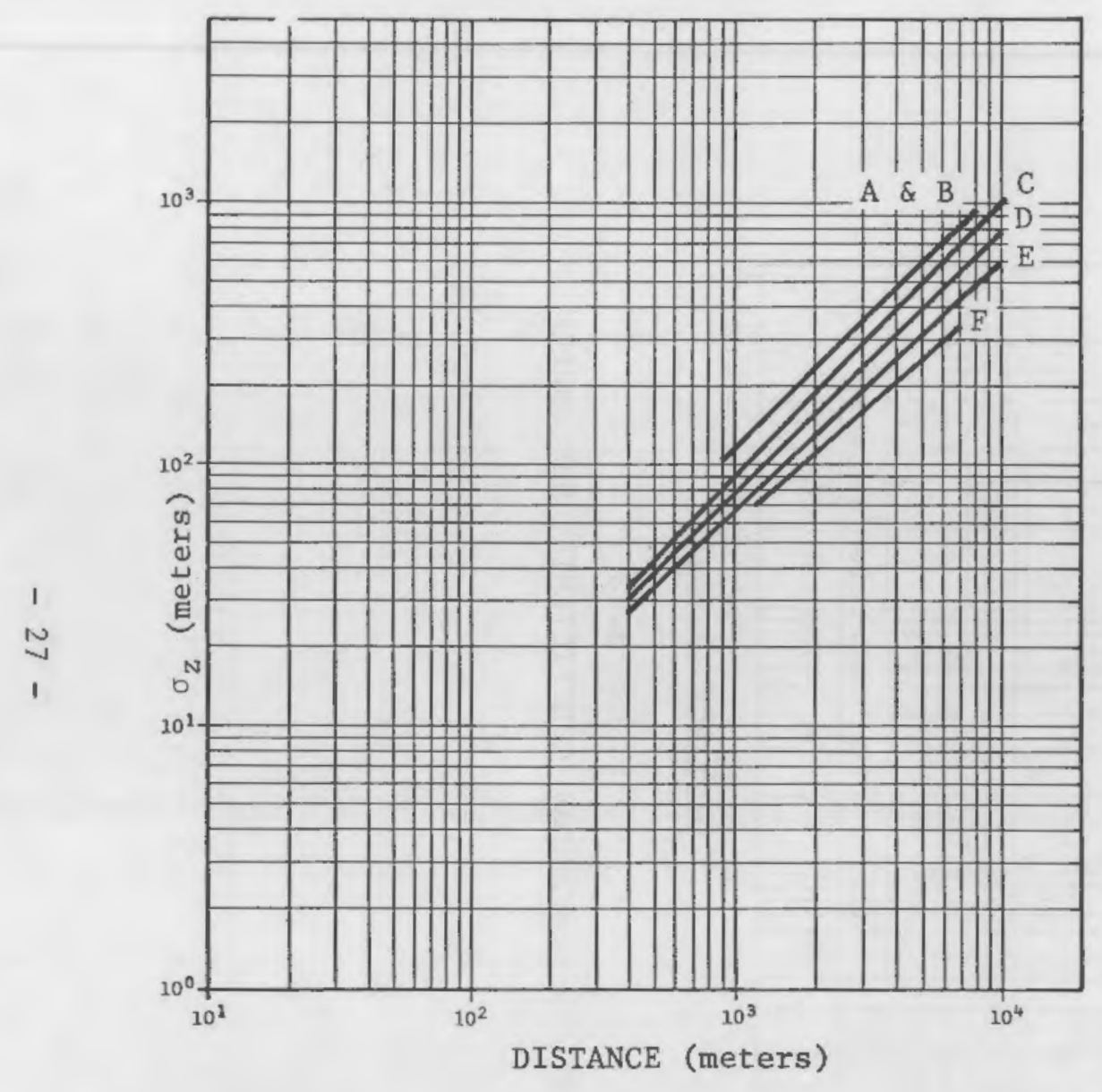

FIGURE 3.16

VERTICAL DISPERSION COEFFICIENTS, MOUNTAIN IRON $\left(\sigma_{\theta}\right.$ STABILITY CLASSES)(AFTER HINDS, 1967)

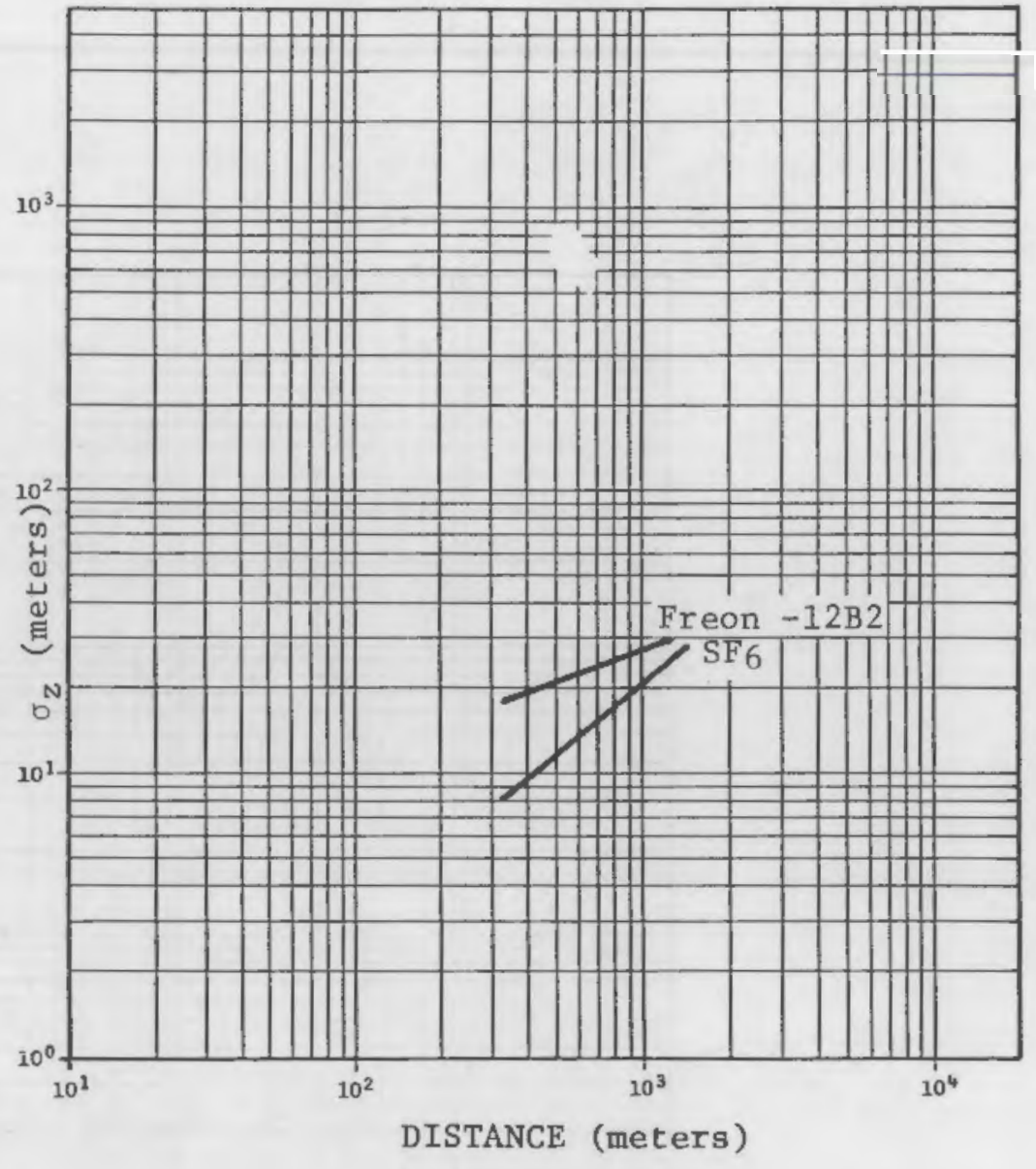

FIGURE 3.17

MILLSTONE, VERTICAL DISPERSION COEFFICIENTS 


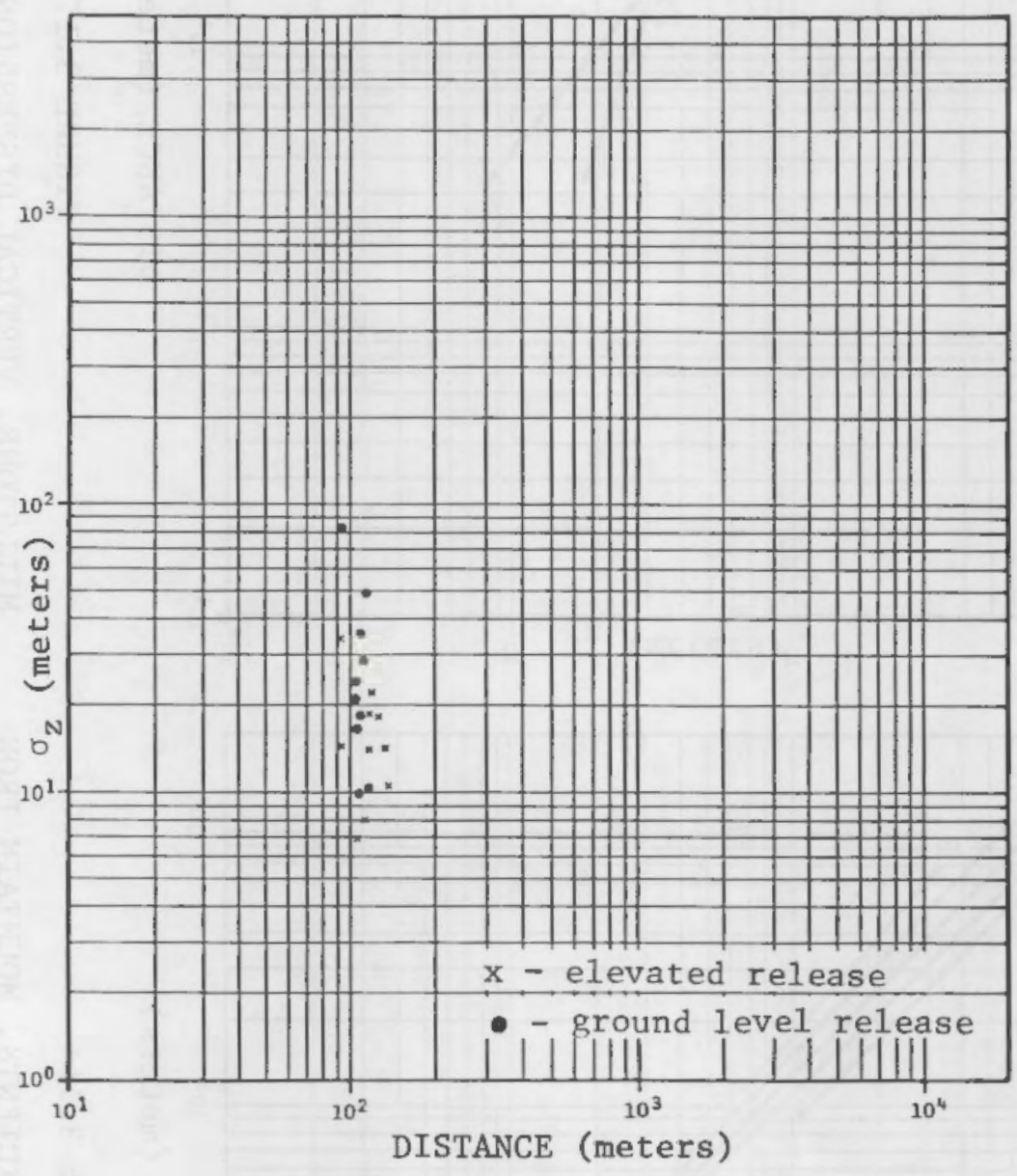

FIGURE 3.18

VERTICAL DISPERSION COEFFICIENTS, SAN ONOFRE 


\subsection{RESULTS}

Dispersion coefficient values have been derived or extracted from existing data sets that were obtained from field measurement programs conducted in coastal regions. Up to this point, the results of these efforts have been presented on a case by case basis and are therefore site specific. In order to provide results to the NRC which are more generally applicable, TRC has examined the results presented in Figures 3.1 through 3.18 to understand and define the similarities and the differences exhibited by the material presented. Experimental design factors inherent in each study, as well as the geographical and topographical differences between the fleld programs, have been compared to derive an objective scheme for classifying and then combining the dispersion coefficient values obtalned from each data set.

Topographical features can be expected to exert a strong influence on the turbulent characteristics of the atmosphere in a given location. The Mountain Iron program and the Ocean Breeze/Dry Gulch experiments provide a good basis for comparing the effects of terrain because they were conducted with essentially the same experimental designs but were performed in regions having much different topography. The dispersion coefficients obtained during the Mountain Iron program (Figure 3.1) are larger for each stability class than the values obtained from efther the Dry Gulch (F1gures 3.2 and 3.3 ) or the Ocean Breeze programs (F1gure 3.4). These differences are attributed to the differences in terrain between the test locations: the Mountain Iron program was conducted $1 \mathrm{n}$ an area of complex terrain (roughness length about 2 meters) while the Dry Gulch and Ocean Breeze programs were conducted in regions that are relatively flat (roughness lengths less than 0.3 meters).

Another important factor for determining the magnitude of the dispersion coefficient values is the duration of the tracer release period. Several authors, including Gifford (1956), Bowne (1973), and Hanna, et al (1982), have described the differences in diffusion rates between smoke "puffs" and smoke "plumes." It can be expected that emissions from a continuous source (a smoke plume) will be affected by a wider spectrum of eddy sizes, than will emissions from an instantaneous source (or smoke puff). This fact is illustrated in Figure 4.1 which was derived from the Camp Cooke results. During Phase A of the experiments, tracer materials was emitted instantaneously from exploding bomblets, while during Phase $\mathrm{C}$ the tracers were emitted continuously for a duration of four minutes. Even with a relatively short difference in release times, a marked difference in resulting dispersion coefficients is evident. 


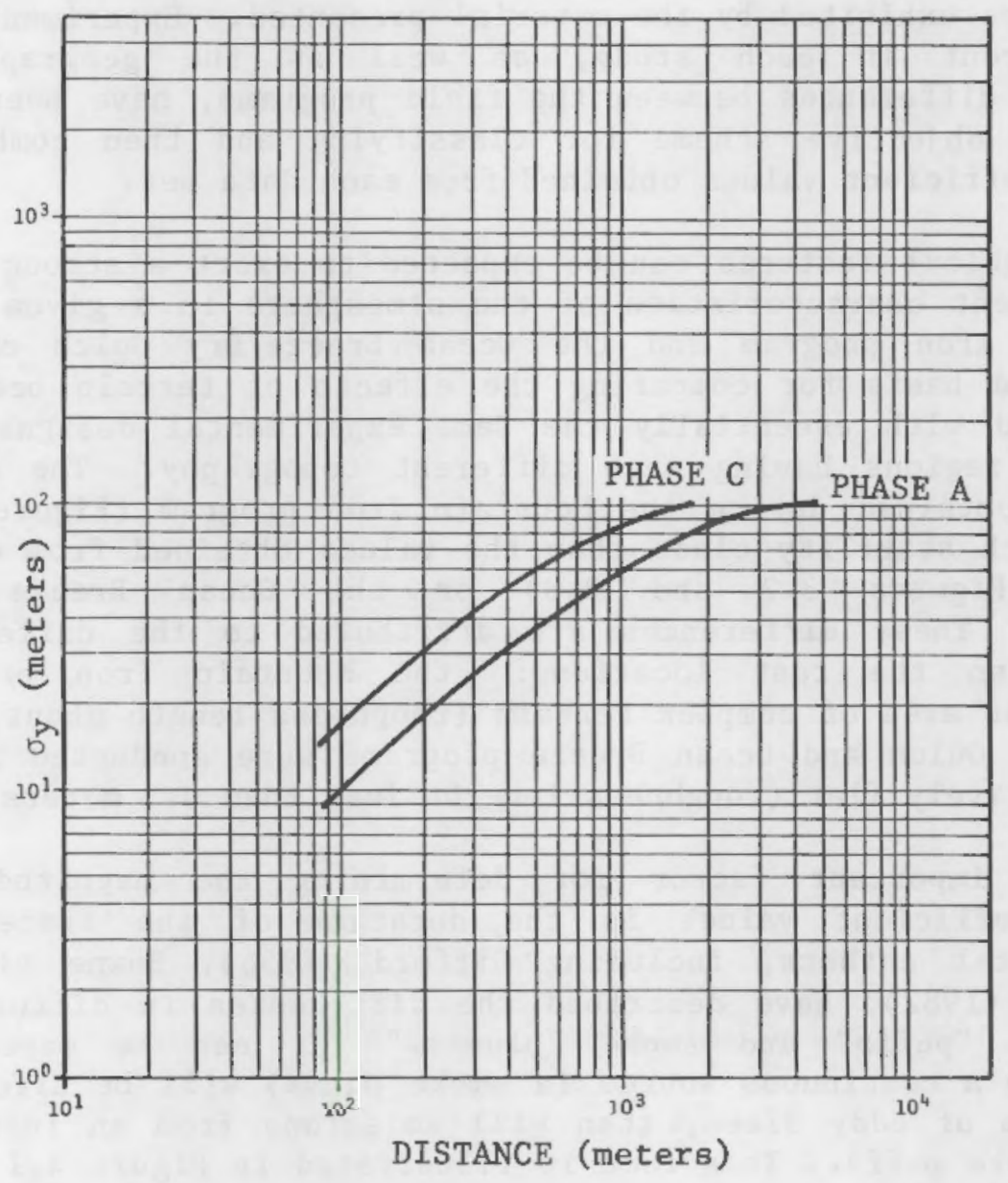

FIGURE 4.1

HORIZONTAL DISPERSION COEFFICIENTS, CAMP COOKE, COMPARISON OF INSTANTANEOUS (PHASE A) VS. CONTINUOUS (PHASE C) TRACER RELEASE 
From these results, the dispersion coefficients obtained from the varlous field programs were categorized according to terrain and release period. The resulting categories are:

- complex terrain/continuous source;

- complex terrain/1nstantaneous source;

- flat terrain/continuous source;

- flat terrain/1nstantaneous source.

The Mountain Iron and North Norway studies fit into the complex terrain/continuous source category. The Dry Gulch and Ocean Breeze studies comprise the flat terraln/continuous release category. The flat terrain/instantaneous release category is represented by the Camp Cooke and the Shoreline 1nstantaneous releases. Unfortunately, complex terrain/instantaneous releases are not represented by any of the existing data sets.

The Millstone and San Onofre data stand apart from any of the above classifications because they were the only tests conducted in the vicinity of man-made structures. The fact that these data were obtained from tests at existing nuclear generating facilities, and because the effects of building wakes and aerodynamic downwash are inherent in the coefficlents derived from these tests, the results from the Millstone and San Onofre tests have been treated as a fifth category.

\subsection{COMPLEX TERRAIN/CONTINUOUS SOURCE}

The horizontal dispersion coefficients derived from the Mountain Iron and Norway data sets were Individually plotted to derive the best-fit lines which comprise the complex terraln/continuous emission source curves presented in Figure 4.2. Superimposed on these results are the classical Pasquill-Gifford dispersion coefficients which serve as a basis for comparison. The resultant curves are simflar to the Mountain Iron curves except the one for A and B stabllity is shifted upward slightly due to inclusion of the Norway data which is comprised of somewhat higher values. In general, the resultant curves are about one stability class more unstable than the $P-G$ curves. It is not surprising that the atmosphere exhfbits greater turbulence (more unstable) in regions of complex terrain as these data seem to Indicate.

A similar procedure was employed to develop the vertical dispersion coefficients for continuous emission sources in complex terrain shown in Figure 4.3. As noted before, the conplex terraln curves are shifted toward the "unstable" range of the P-G values, with the exception of the most unstable classes $A$ and $B$. It is also noteworthy that the dispersion coefficients derived in this analysis exhibit a much narrower range of values between the most unstable categorles and the most stable, as compared to the $P-G$ curves. 


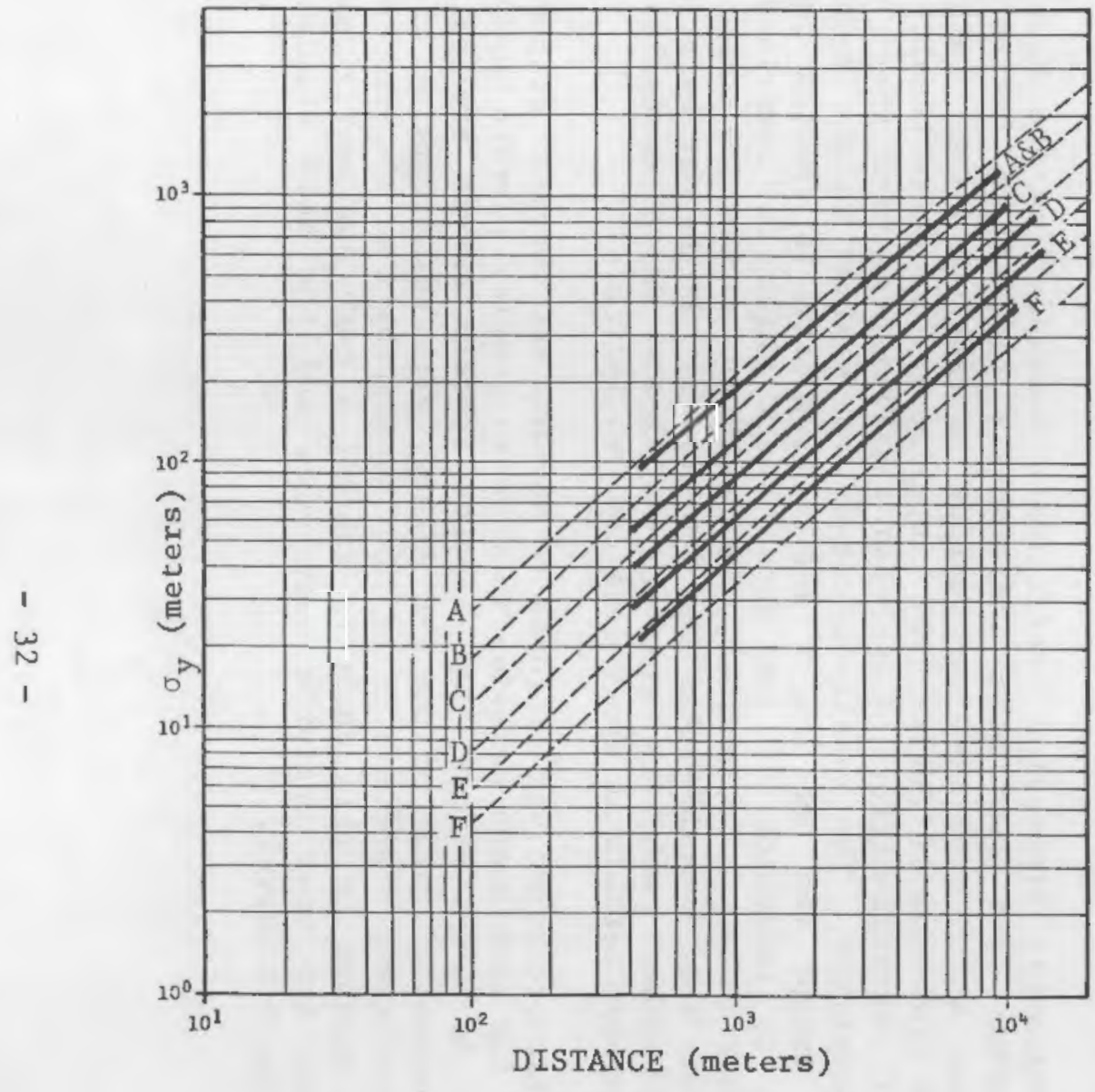

FIGURE 4.2

HORIZONTAL DISPERSION COEFFICIENTS, COMPLEX TERRAIN CONTINUOUS SOURCE $\left(\sigma_{\theta}\right.$ STABILITY CLASSES)

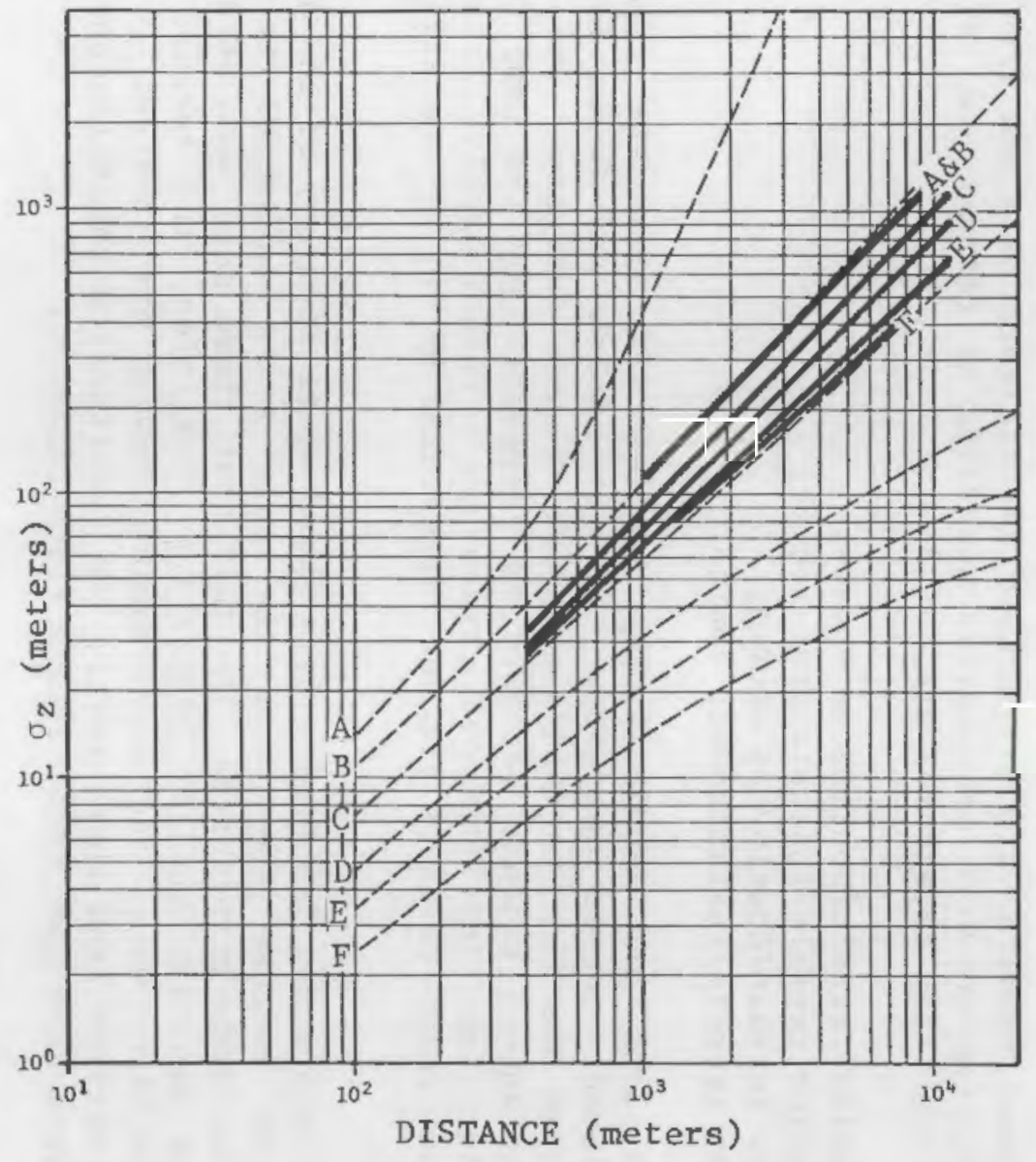

FIGURE 4.3

VERTICAL DISPERSION COEFFICIENTS, COMPLEX TERRAIN - CONTINUOUS SOURCE $\left(\sigma_{\theta}\right.$ STABILITY CLASSES) 


\subsection{FLAT TERRAIN/CONTINUOUS SOURCE}

The Ocean Breeze and Dry Gulch data sets were combined to yleld the dispersion coefficients applicable to continuous emission sources located in flat terrain as shown in Figure 4.4. The results compare favorably with the $P-G$ data as should be expected. Unfortunately there are no data available in this case for stable atmospheres.

The vertical dispersion coefficients for continuous releases in flat terrain are shown in Figure 4.5. As with the results from tests in complex terrain, the resultant curves exhibit a narrower range of values than the $P-G$ data. Another interesting finding is the tendency for the curves to level off at greater downwind distances indicating that the rate of plume growth decreases at greater distances.

\subsection{FLAT TERRAIN/INSTANTANEOUS SOURCE}

The Camp Cooke diffusion trials provided the only data avallable to describe dispersion of instantaneous emission sources. As mentioned, the Camp Cooke experiments were performed in predominantly flat terrain, and under neutral atmospheric conditions. The horizontal dispersion coefficients derived from these data are shown in Figure 4.6, and the vertical coefficients appear in Figure 4.7. Again the data exhibit a tendency to level off at lncreasing downwind distance from the source in sharp contrast to the $P-G$ curves. Unfortunately, only neutral atmospheric stablity conditions are represented, and no programs have been identifled which have tested instantaneous sources in complex terrain.

\subsection{ELEVATED SOURCE/PLUME DOWNWASH}

Dispersion of contaminants emitted into the atmosphere in the vicinity of a power plant complex has been studied at the Millstone and San Onofre Nuclear Generating Stations. Figures 4.8 and 4.9 represent horizontal and vertical dispersion coefficients from data obtained in the vicinity of man-made structures. Although the tests were performed during stable atmospheric conditions, the curves are shifted into the 'unstable regions' of the $P-G$ data sets. This is undoubtedly attributable to the enhanced turbulence created by the plant complex. In fact many of the Millstone tests were performed during conditions of aerodynamic downwash, with the tracer being entrained into the building wake cavity. Such conditions can be expected to cause a rapid, initial horizontal and vertical spread of an effluent plume.

\subsection{SUMMARY OF RESULTS}

In general, the dispersion coefficient curves derived from the tests performed in coastal regions are more tightly grouped than are the more traditionally accepted values. In other words the data presented in this analysis exhibit a much smaller range of values between the most 


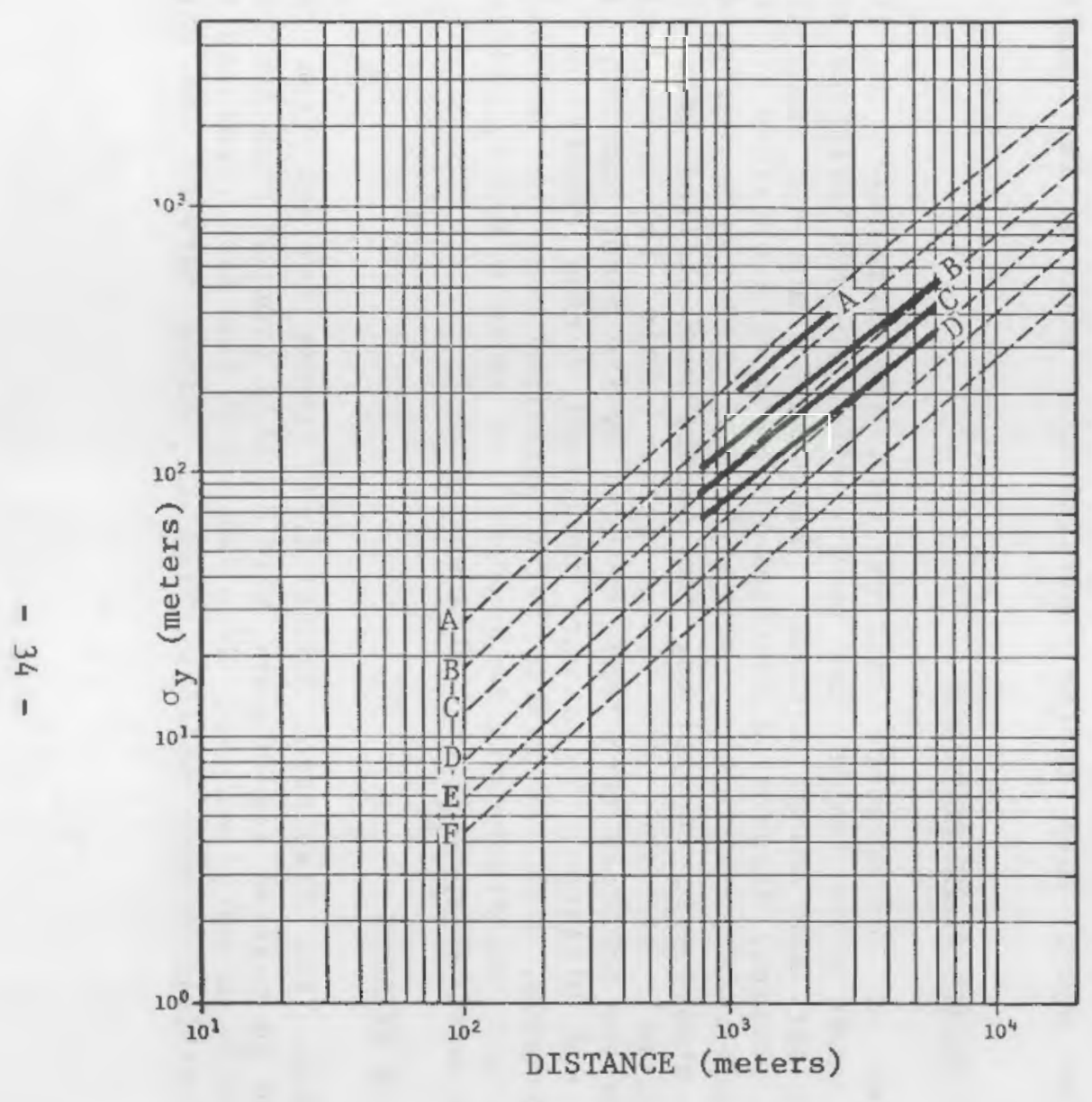

FIGURE 4.4

HORIZONTAL DISPERSION COEFFICIENTS, FLAT TERRAIN CONTINUOUS SOURCE $\left(\sigma_{\theta}\right.$ STABILITY CLASSES)

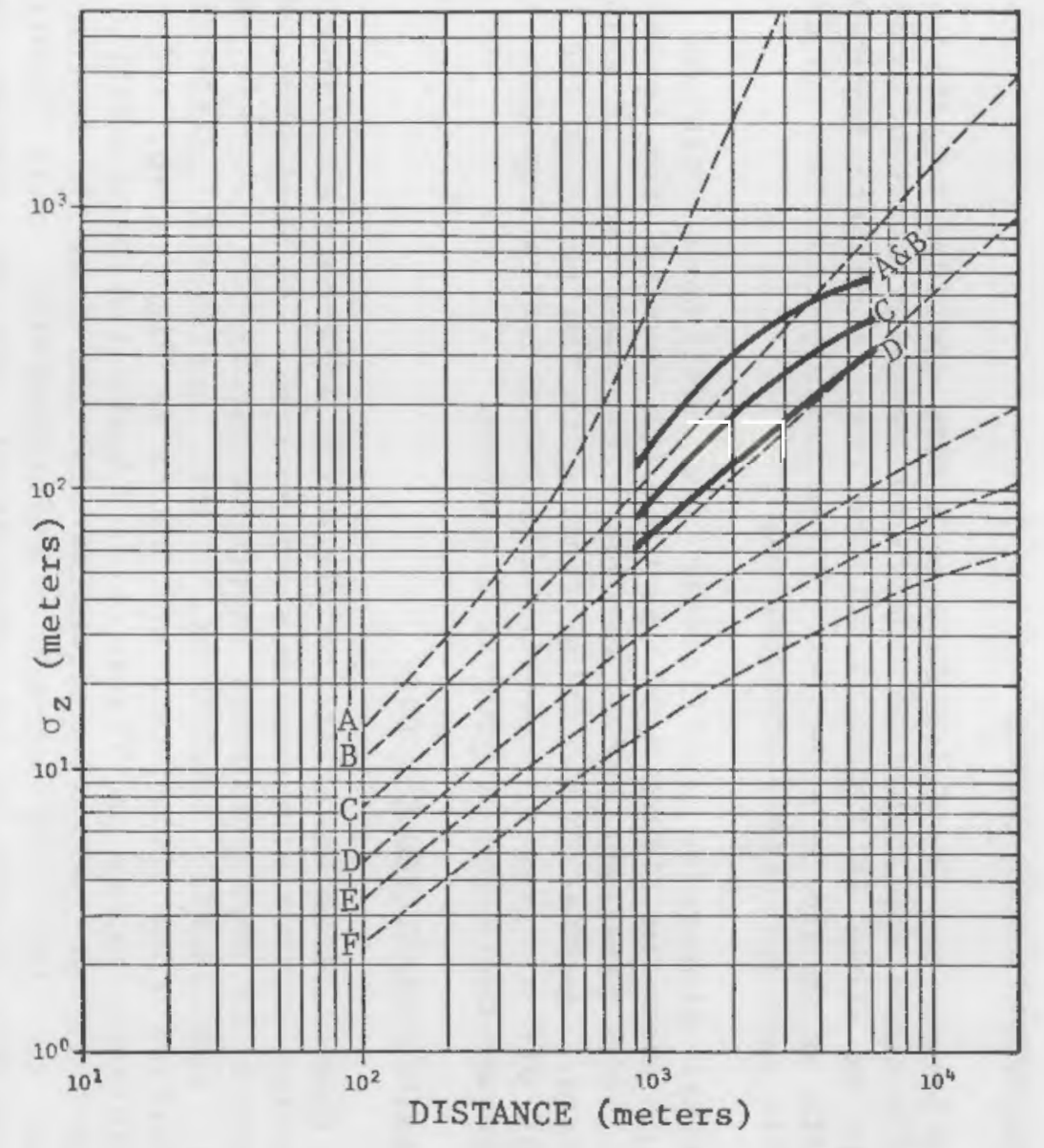

FIGURE 4.5

VERTICAL DISPERSION COEFFICIENTS, FLAT TERRAIN CONTINUOUS SOURCE ( $\sigma_{\theta}$ STABILITY CLASSES) 


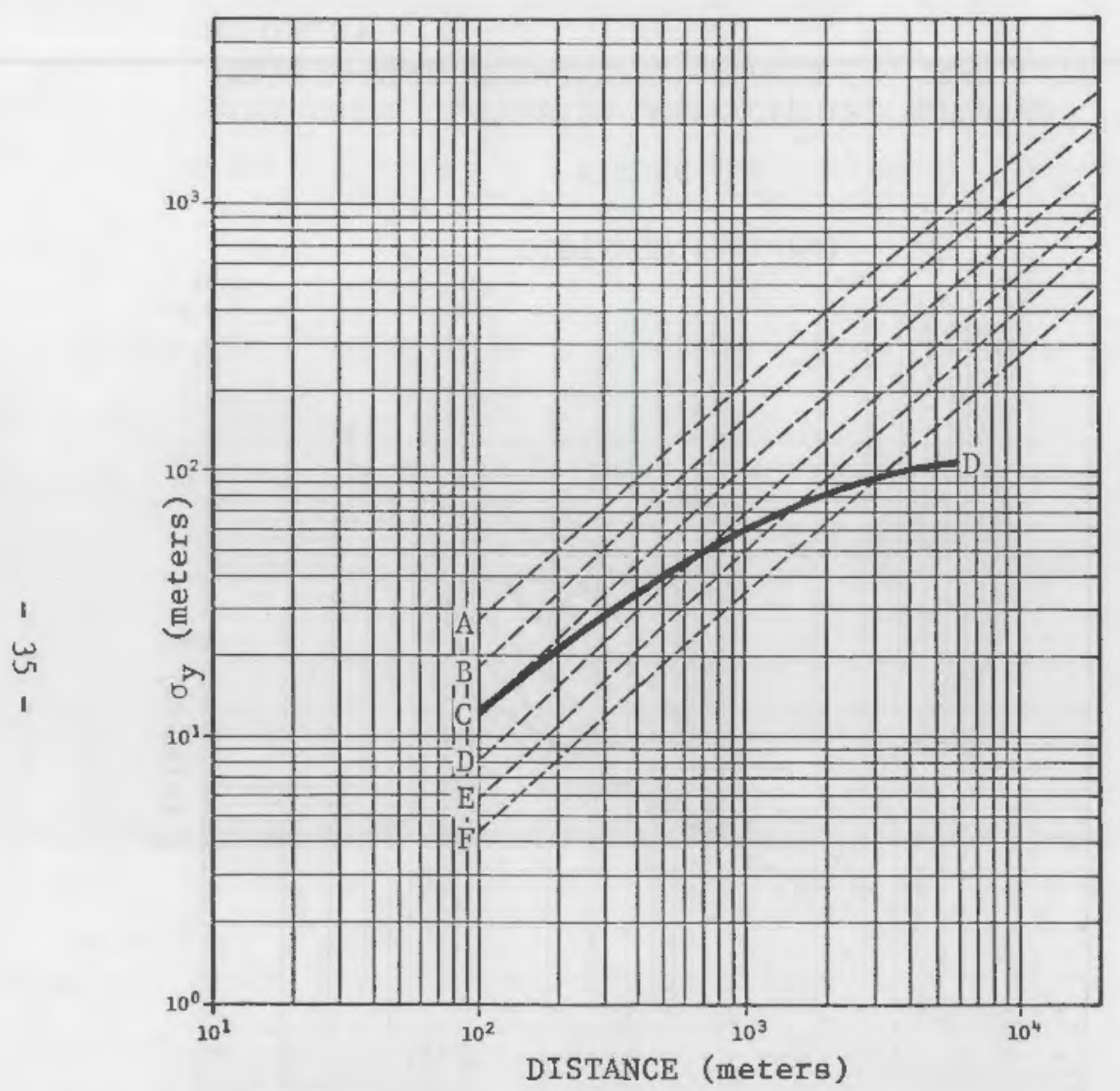

FIGURE 4.6

HORIZONTAL DISPERSION COEFFICIENTS, FLAT TERRAIN INSTANTANEOUS SOURCE ( $\sigma_{\theta}$ STABILITY CLASS)

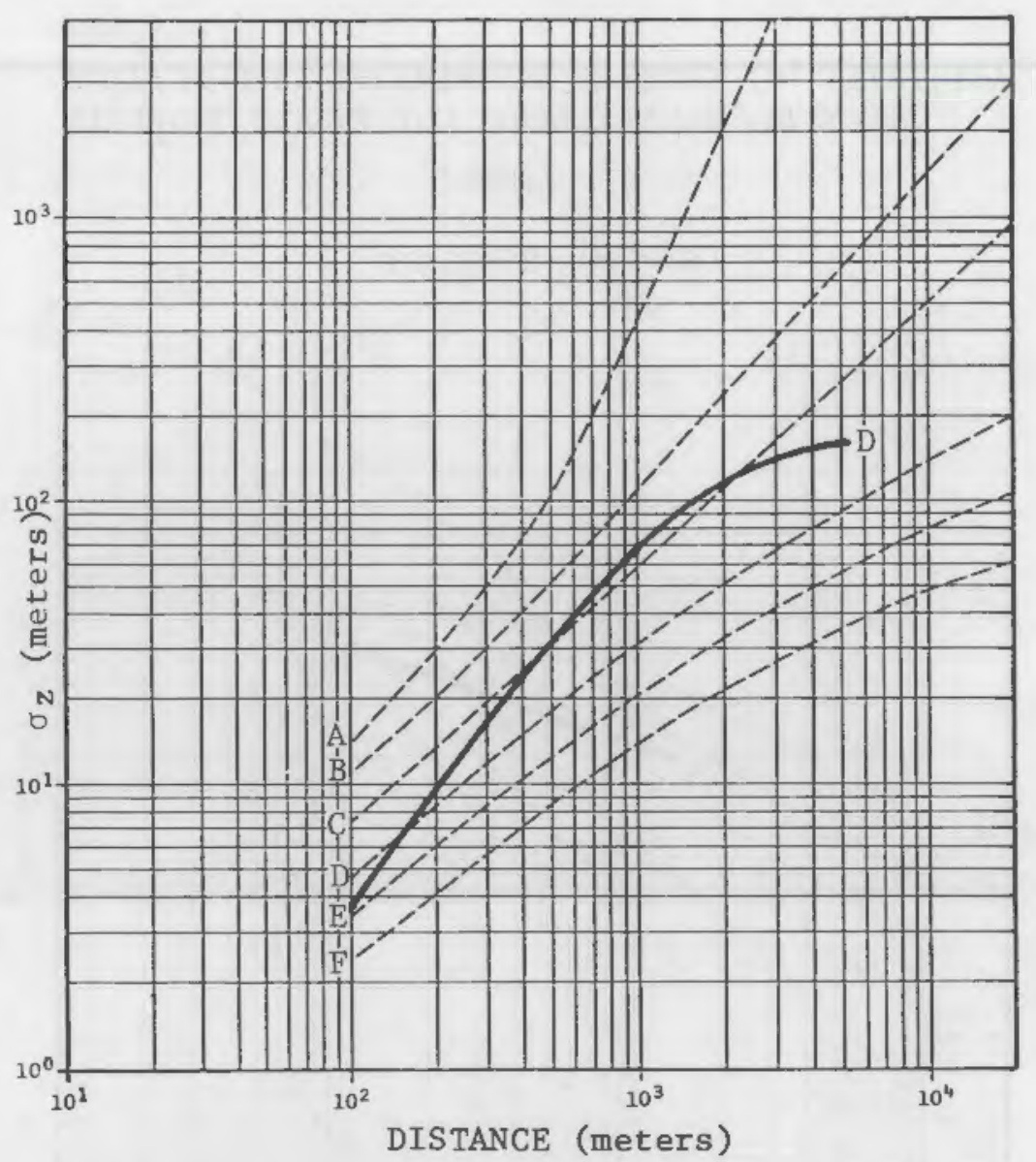

FIGURE 4.7

VERTICAL DISPERSION COEFFICIENTS, FLAT TERRAIN INSTANTANEOUS SOURCE $\left(\sigma_{\theta}\right.$ STABILITY CLASS) 


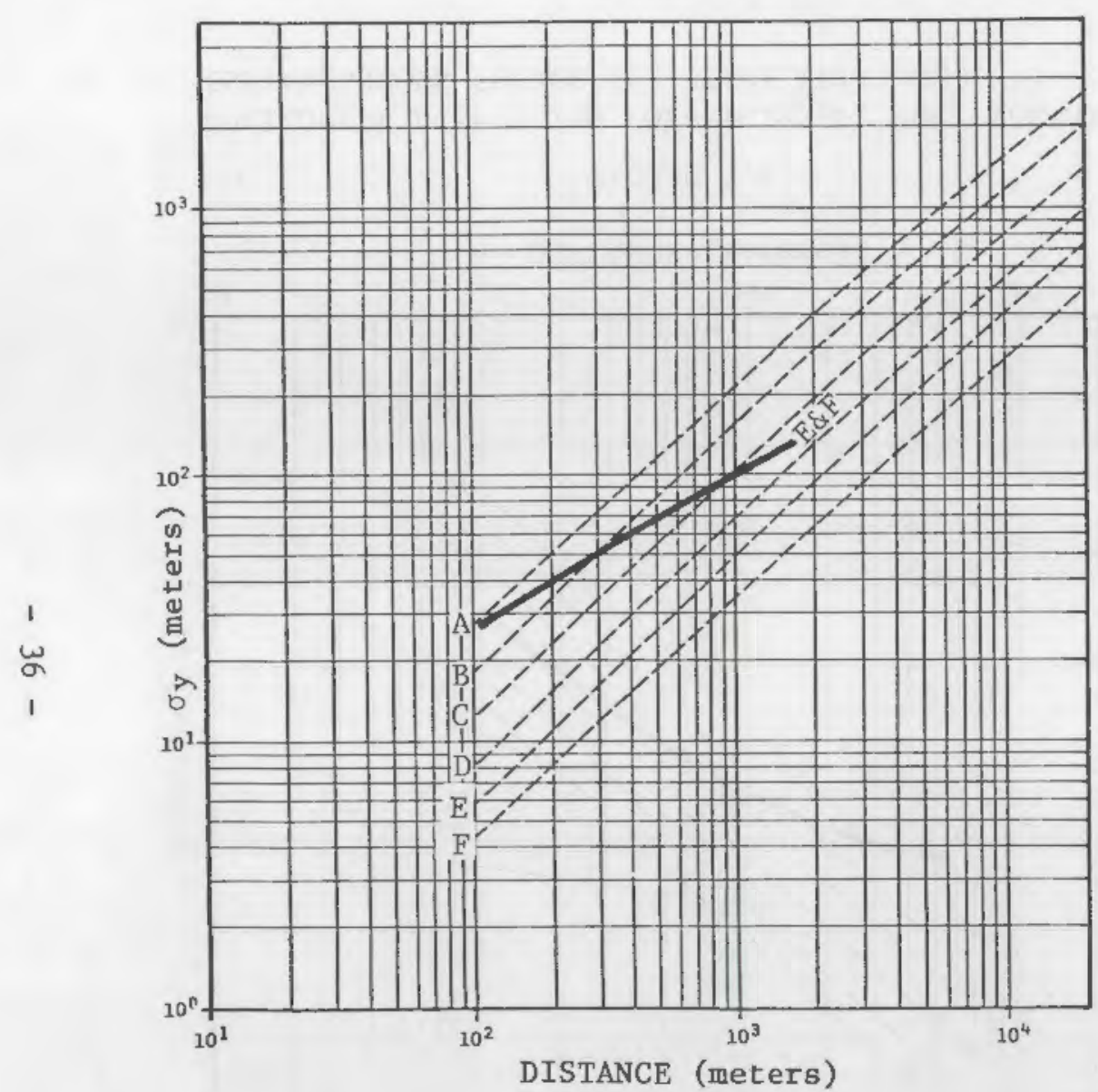

FIGURE 4.8

HORIZONTAL DISPERSION COEFFICIENTS, ELEVATED RELEASE-WAKE ENTRAINMENT EFFECTS ( $\sigma_{\theta}$ STABILITY CLASSES)

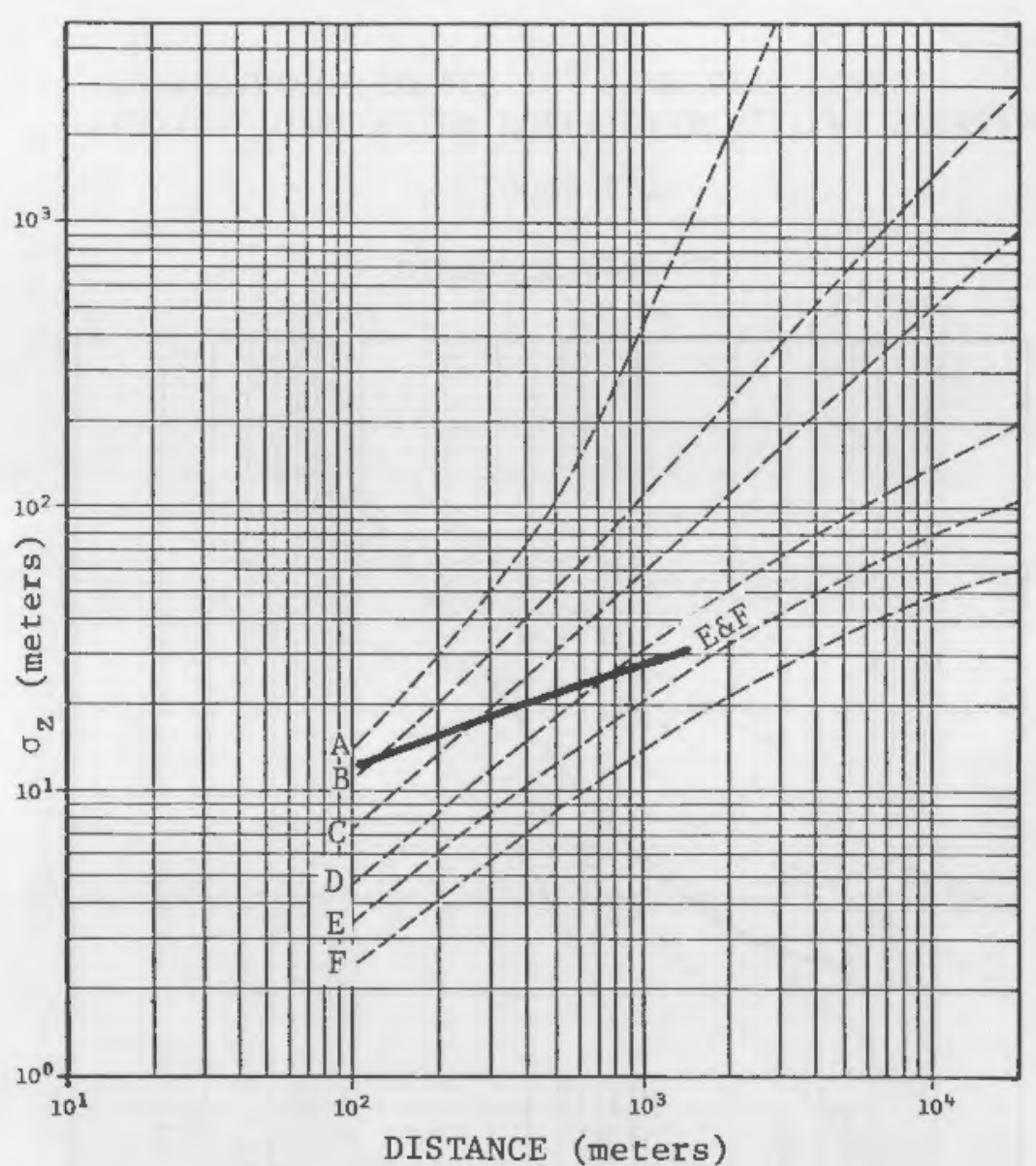

FIGURE 4.9

VERTICAL DISPERSION COEFFICIENTS, ELEVATED RELEASE-WAKE ENTRAINMENT EFFECTS $\left(\sigma_{\theta}\right.$ STABILITY CLASSES) 
unstable categories and the most stable ones, than do the widely used Pasquill-Gifford values. A decreased growth rate of an effluent plume at distances greater than about one kilometer from its emission source is also indicated by these results most notably for instantaneous sources.

The departures of the presented curves from the more classical values can be explained, for the most part, by variations of well examined factors, such as terrain, release duration, release height, and other local effects such as aerodynamic downwash. It should be noted that these data do not exhibit effects that can easily be attributed to the coastal environment from which they were obtalned. It could be argued that the data employed in this study are biased, by experimental design, towards representation of "steady-state" conditions, which then minimize those influences that are uniquely coastal in nature. The resulting data base is therefore incomplete because it does not represent important coastal features, such as the diurnal sea/land breeze cycle, or the growth of the turbulent internal boundary layer, which play a pivotal role In determining the dispersive potential of the atmosphere in coastal regions. 
TRC Environmental Consultants have conducted a detailed review and analysis for the U.S. Nuclear Regulatory Commission of existing data from previously conducted field programs related to atmospheric dispersion processes in coastal reglons. The results of this analysis, which have been presented in graphical form, consist of both horizontal and vertical dispersion coefficients that are representative of coastal conditions experienced at the locations of existing or proposed nuclear generating facilities. The existing data base has been found to yleld a good representation of dispersion conditions which might affect continuous emissions in a variety of terrain. Atmospheric conditions that would be expected during daylight hours are particularly well represented in the existing data base.

In TRC's opinion, the existing data base does not provide an adequate representation of conditions which are not "steady state." The experimental design of most of the measurement programs conducted to date intentionally avoided conditions that were not steady state, such as rapid wind shifts, trapping, or fumigation conditions, because of the Inherent difficulty of performing such measurements. Other gaps which are evident in the existing data base include stable, nighttime conditions, instantaneous emission releases, and offshore flow conditions. Possibly the largest void in the measurements performed to date is the almost complete lack of tests to measure the vertical growth of effluent plumes. As previously mentioned, the vertical dispersion coefficlents presented in this report were almost exclusively derived from measurements of horizontal dispersion using the Gaussian plume model.

The results of this analysis have been compared to the well-known Pasquill-Gifford dispersion coefficients and the departures from the classical results can be explained by traditional factors such as differences of terraln, release duration, and local effects such as aerodynamic downwash conditions. Other conclusions can be made from this analysis:

- good agreement is evident between the Pasquil1-Gifford coefficient values and those derived from tests performed using a continuous emission source located in flat terrain;

- results obtained from tests in complex terrain indicate a greater degree of turbulence than those from flat terrain as the coefficient values are greater in magnitude for each stability class and downwind distance; 
- Instantaneous (puff) releases experience a different spectrum of turbulent eddy sizes than do continuous (plume) emission releases, as evidenced by the lower dispersion coefficients derived from experiments using instantaneous releases;

- a decrease in plume growth rates with increasing downwind distance is indicated by the leveling off of many of the dispersion coefficient curves at downwind distances greater than one kilometer;

- a smaller range of coefficlent values, between the most stable cases and the most unstable, is indicated by these results as compared to the Pasquill-Gifford curves.

Based on the findings of this report, in regards to both the information that is well represented by existing data and the information that is poorly represented, the following recommendations are made for future work on coastal dispersion:

- detailed measurements of vertical dispersion in coastal regimes should be performed;

- detalled measurements of instantaneous point source emissions, in a varlety of terrain conditions, should be performed;

- more information is needed regarding dispersion in stable atmospheres in coastal reglons;

- better information on dispersion during nonsteady-state conditions, and especially conditions which are uniquely coastal in nature (such as the diurnal sea/land breeze cycle, and the turbulent internal boundary layer), should be obtained;

- measurements of dispersion at very short (less than one kilometer) or very long (greater than five kilometers) downwind distances should be performed;

- a standardized method of atability measurement and classification should be employed to insure that the results from future measurement programs are easily intercomparable. 
AeroVironment Incorporated, 1980: Data Submission for Offshore Tracer Study in Ventura County, Volume I - Tracer Cas and Meteorological Data. Report Number DP-80-056. Pasadena, California, $220 \mathrm{pp}$.

AeroVironment Incorporated, 1980: Data Submission for offshore Tracer Study In Ventura County, Volume II - Doppler Acoustic Radar Data. Report Number DP-80-056. Pasadena, California, 381 pp.

Bierly, E. W. and E. W. Hewson, 1963: Atmospheric Diffusion Studies near a Lake Shore. Journal of Applied Meteorology, Volume 2, pp. 390-396.

Bowne, N. E., 1973: Diffusion Rates. Proceedings of the 66th Annual Meeting of the Alr Pollution Control Association (\$73-13.0), Chicago, Illinois, 4 pp.

Brown, L., 1980: Proposed Revision 1 to Regulatory Guide 1.23 Meteorological Programs in Support of Nuclear Power Plants. U.S. Nuclear Regulatory Commission, Office of Standards Development, Task SS 926-4, Washington D.C., 34 pp.

Cox, E. L., W. D. Foster, and V. S. Palmer, 1958: Comparison of Simulant Decay Rates and Area Coverages (V). U.S. Army Chemfcal Corps Research and Development Command, Report Number 287, Frederick, Maryland, 84 pp.

Cramer, H. E., R. K. Dumbauld, F. A. Record, and R. N. Swanson, 1970: Titan III-D Toxicity Study. GCA Corporation for the Department of the Alr Force, Report Number TR-70-3-A, pp. 30-54.

Cramer, H. E., H. L. Hamilton, G. M. DeSanto, 1965: Atmospheric Transport of Rocket Motor Combustion By-Products, Volume 1 - Data Analysis and Prediction Technfque. GCA Corporation (Contract Number N123[61756]34567[PMR]), 156 pp.

Cramer, H. E., H. L. Hamflton, G. M. DeSanto, 1965: Atmospheric Transport of Rocket Motor Combustion By-Products, Volume 2 - Experimenta1 Design and Field Installation. GCA Corporation (Contract Number N123[61756]34567[PMR]), 46 PP.

Cramer, H. E. and F. A. Record, 1970: Diffusion Studies at the Diablo Canyon Site. GCA Corporation for Pacific Gas and Electric Company, 43 pP.

Daubek, H. G., W. L. Dotson, J. V. Ramsdell, P. W. Nickola, 1969: The Mountain Iron Diffusion Program: Phase II, South Vandenberg: Volume 3, Battelle - Pacific Northwest Laboratories (BNWL-572, Volume 3), 223 pp. 
Eldsvik, K. J. and F. K. Hansen, 1972: Turbulent Diffusion in the Surface Boundary Layer of Near Neutral Stratifled Flows Along Four Valleys. Interim Report VM-6 Forsvarets Forskningsinstitutt, Norwegian Defense Research Institute, Kjeller, Norway, $50 \mathrm{pp}$.

Ettenhe1m, Jr., G. P. and C. L. Crum, 1967: Matagorda Deposition Tra11s. Meteorology Research, Inc. Report Number MRI67-FR-468, Altadena, Californta, 76 pp.

Gifford, F. A., 1956: Relative Atmospheric Diffusion of Smoke Puffs. Research and Development Division, Atomic Energy Commission, Oak Ridge, Tennessee, $14 \mathrm{pp}$.

Gifford, F. A., 1976: Turbulent Diffusion-Typing Schemes: A Review. Nuclear Safety, Volume 17, 20 pp.

Gifford, F. A., 1982: Long-Range Plume Disperston: Comparisons of the Mount Isa Data with Theoretical and Emplrical Formulas. Atmospheric Environment, Volume 16, Number 6, pp. 1583-1586.

Gotaas, Y., 1975: Atmospheric Dispersion in Valleys, VM-34, Part I, II Interim Report Forsvarets Forskningsinstitutt, Norwegian Defense Research Institute, Kje1ler, Norway, Part I - 60 pp., Part II - 19 pp.

Hage, K. D., G. Arnason, N. E. Bowne, P. S. Brown, H. D. Entrekin, M. Levitz, and J. A. Sekorsk1, 1966: Particle Fallout and Dispersion in the Atmosphere, Final Report. The Travelers Research Center, Inc. for the Sandia Corporation, Wethersfield, Connecticut, 102 pp.

Hallanger, N. L., G. R. Herd, G. Shortley, and R. L. Stearman, 1959: Further Study of the Camp Cooke Aeroso1 Dissemination Tralls. Booz Allen Applied Research, Inc. Report Number BAARINC-PRO-R-3, Bethesda, Maryland, 97 pp.

Hamflton, H. L., 1965: Atmospheric Transport of Rocket Motor Combustion By-Products, Volume 3 - Data Supplement. GCA Corporation (Contract Number N123[61856]34567[PMR]), 204 PP.

Hanna, S. R., G. A. Briggs, and R. P. Hosker, 1982: Handbook on Atmospheric Diffusion. Atmospheric Turbulence and Diffusion Laboratory, National Oceanic and Atmospherlc Administration, Oak Ridge, Tennessee, $102 \mathrm{pp}$.

Haugen, D. A. and J. J. Fuquay, 1963: The Ocean Breeze and Dry Gulch Diffusion Programs, Volume I, Hanford Laboratorles, Contract Number AT(45-1)-1350 (Atomic Energy Commission), 240 pp. 
Haugen, D. A. and J. H. Taylor, 1963: The Ocean Breeze and Dry Gulch Diffusion Program, Volume II, Air Force Cambridge Research Laboratories, Contract Number WS $107 \mathrm{~A}-2,100$ pp.

Hewson, E. W., G. C. G111, and E. W. Bier1y, 1960: Atmospheric Diffusion Study at the Enrico Fermi Nuclear Reactor Site. Progress Report No. 2 (under contract with the Power Reactor Development Company), Department of Civil Englneering Meteorological Laboratories, University of Michigan.

Hinds, W. T. and P. W. Nickola, 1967: The Mountain Iron Diffusion Program: Phase I, South Vandenberg: Volume 1, Battelle-Pacific Northwest Laboratorfes (BNWL-572 Volume 1), 276 pp.

Hinds, W. T. and P. W. Nickola, 1968: The Mountain Iron Diffusion Program: Phase I, South Vandenberg: Volume 2, Battelle-Pacif1c Northwest Laboratories (BNWL-572 Volume 2), 258 pp.

Johnson, W. B., E. Shelar, R. E. Ruff, H. B. Singh, and L. Salas, 1975: Gas Tracer Study of Roof-Vent Effluent Diffusion at Millstone Nuclear Power Station. Stanford Research Institute, Menlo Park, California, SRI Project Number 3588, 295 pages.

Lamb, B. K., A. Lorenzen, and F. H. Sha1r, 1978: Atmospheric Dispersion and Transport within Coastal Regions - Part I. Tracer Study of Power Plant Emissions from the Oxnard Plain. Atmospheric Environment, Volume 12, pp. 2089-2100.

Lamb, B. K., F. H. Shair, and T. B. Smith, 1978: Atmospheric Dispersion and Transport within Coastal Regions - Part II. Tracer Study of Industrial Emissions in the California Delta Region. Atmospheric Environment, Volume 12, pp. 2101-2118.

Martinez, E. L., 1965: Special Study for the Determination of FP Dissemination Efficiency of the Modified E61R4 Bomblet. U.S. Army Test and Evaluation Command, Dugway, Utah, 19 pp.

Miller, R. L., 1966: Victoria Diffusion Trials, Volume I. Meteorology Research, Inc., Report Number MRI66-FR-374, Altadena, California, 184 pp• 
REFERENCES (Cont'd)

M11ler, R. L., 1966: Victoria Diffusion Trails, Volume II, Part A. Meteorology Research, Inc., Report Number MRI66-FR-374, Altadena, Callfornia, 332 pp.

Miller, R. L., 1966: Victoria Diffusion Trials, Volume II, Part B. Meteorology Research, Inc., Report Number MRI66-FR-374, Altadena, California, pp. 334-658.

Minott, D. H. and D. L. Shearer, 1977: Development of Vertica1 Dispersion Coefficlents for Shoreline Environment. TRC Project Number 72607, Report Number C00-4026-2, Wethersfield, Connecticut.

Minott, D. H., D. L. Shearer, and R. S. Marker, 1977: Development of Vertical Dispersion Coefficlents for Deep-Valley Terrain. TRC Project Number 72607, Report Number C00-4026-3, Wethersfle1d, Connecticut.

Minott, D. H. and D. L. Shearer, 1979: Measurements of the Vertical Dispersion Rate in Deep-Valley Terrain. Preprints of the Fourth Symposium on Turbulence, Diffusion, and Air Pollution, Number 4.10, Reno, Nevada. American Meteorological Society, Boston, Massachusetts, pp. 229-236.

Pasqui11, F., 1976: Atmospheric Dispersion Parameters in Gaussian Modeling, Part II: Possible Requirements for Change in the Turner Workbook Values. North Carolina State University for the U.S. Environmental Protection Agency, Raleigh, North Carolina, 44 pp.

Rappolt, T. J., 1981: Summary Report: Synopsis and Critique of $\mathrm{SF}_{6}$ Tracer Gas Experiments Conducted by BLM and CARB in the Santa Barbara Channe1. Energy Resources Company, Inc., LaJolla, California, 28 pp.

Rappolt, T. J., 1981: A Synopsis and Critique of SF 6 Tracer Gas Experiments Conducted by BLM in the Santa Barbara Channe1. Energy Resources Company, Inc., LaJolla, California, 35 pp.

Raynor, G. S., R. M. Brown, and S. SethuRaman, 1976: A Comparison of Diffusion from a Small Island and a Nearby Ocean Site. Preprints of the Conference on Coastal Meteorology, Virginia Beach, Virginia. American Meteorological Soc1ety, Boston, Massachusetts.

Raynor, G. S., R. M. Brown, and S. SethuRaman, 1976: Experimental Data from Coastal Diffusion Tests. Brookhaven National Laboratories, Upton, New York, Report Number BNL-21998, 502 pp. 
Raynor, G. S., P. Michael, R. M. Brown, and S. SethuRaman, 1975: Studies of Atmospheric Diffusion from a Nearshore Oceanic Site. Journal of Applied Meteorology, Volume 14, pp. 1080-1094.

Septoff, M., L. J. Brunton, and L. H. Teuscher, 1977: Results of an Offshore Dispersion Program Conducted at the San Onofre Nuclear Generating Station. Preprints of the Joint Conference on Applications of Air Pollution Meteorology, Salt Lake City, Utah. Amerfcan Meteorological Society, Boston, Massachusetts.

Shearer, D. L. and R. J. Kaleel, 1982: Critical Review of Studies on Atmospheric Dispersion in Coastal Regions. TRC Environmental Consultants, Inc. for the Unfted States Nuclear Regulatory Commission, Englewood, Colorado, 57 pp.

Shearer, D. L., D. H. Minott, and G. R. H1lst, 1977: Development of Vertical Dispersion Coefficients for Rolling Terrain Environments. TRC Project Number 72607, Report C00-4062-1, Wethersfleld, Connecticut.

Slade, D. H., 1968: Meteorology and Atomic Energy. Prepared for the United States Atomic Energy Commission, 445 pp.

Smedman-Hogstrom, A. S. and U. Hogstrom, 1978: A Practical Method for Determining Wind Frequency Distributions for the Lowest $200 \mathrm{~m}$ from Routine Meteorological Data. Journal of Applied Meteorology, Volume 17, pp. 942-953.

Smith, T. B., 1964: Micrometeorological Investigation of Naval Missile Facility-Point Argue11o, California. MRI 64 FR-167, Volumes I and II, Final Report, Contract Number (123)-(61756) 32885A(PMR), Meteorology Research, Inc., Altadena, California.

Smith, T. B. and K. M. Beesmer, 1967: Bolsa Island Meteorologica1 Investigation. Meteorology Research, Inc., Report Number MRI67-FR-650, 57 pp.

Smith, T. B. and B. L. Niemann, 1969: Shoreline Diffusion Program. Oceanside California, Meteorology Research, Inc., Report Number MR169 FR-860, 3 volumes.

Smith, T. B. and M. A. Wolf, 1963: Vertical Diffusion from an Elevated Line Source over a Variety of Terra1ns. Part A - Final Report to Dugway Proving Ground, Meteorology Research, Inc., Contract Number DA-42-007-CML-545, Report Number MR163-FR-71, 40 pp. 


\section{REFERENCES (Cont'd)}

Turner, D. B., 1971: Workbook of Atmospheric Dispersion Estimates. A1r Resources Field Research Office, Public Health Service, Cincinnati, Ohio, 84 pp.

U.S. Environmental Protection Agency, October 1980: Guideline on Afr Quality Models--Proposed Revisions, Research Triangle Park, North Carollna, 59 pp.

Vaughan, L. M., 1967: Matagorda Deposition Trials - Diffusion and Deposition of Large Particles with Fall Velocities in the Range of 10 to $50 \mathrm{~cm} / \mathrm{sec}$. Metronics Associates, Inc., Technical Report Number 140, Palo Alto, Callfornia, 51 pp.

Vaughan, L. M., 1966: Particulate Diffusion, 1965 Victoria Diffusion Trials. Metronics Associates, Inc., Technical Report Number 126, Palo Alto, California, 33 pp.

Weber, A. H., 1976: Atmospheric Diapersion Parameters in Gaussian Plume Modeling, Part I: Review of Current Systems and Possible Future Developments. North Carolina State University for the U.S. Environmental Protection Agency, Raleigh, North Carolina, 59 pp.

Wolfe, Jr., E. K. and W. W. Dorrell, 1956: Comparison of Simulant Decay Rates in Field Tests (U). Chemical Corps Research and Development Command, Blological Warfare Laboratories Assessment Division, Special Report Number 273, Fredrick, Maryland, 96 pp. 


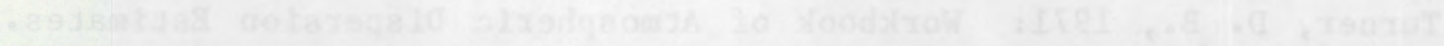

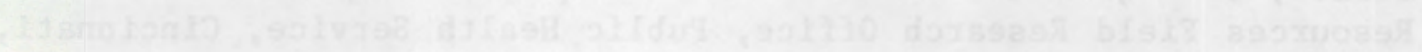

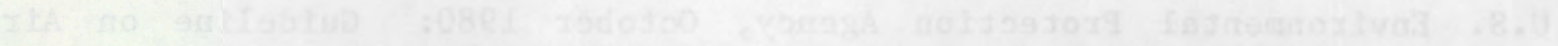

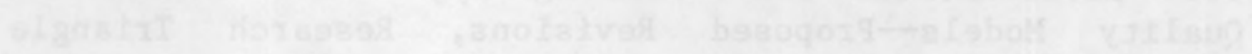

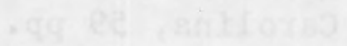

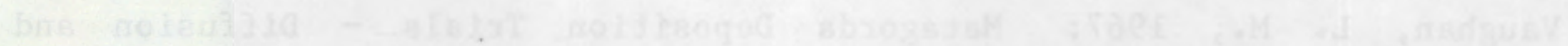

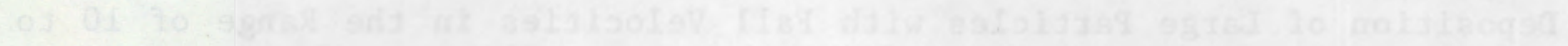

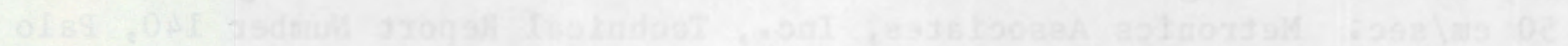

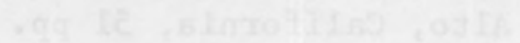

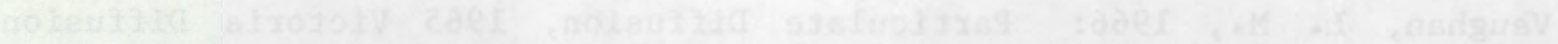

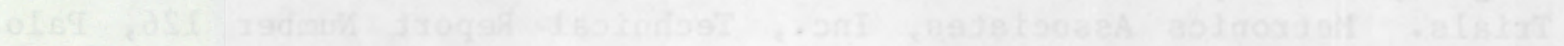

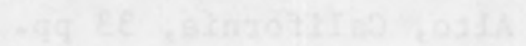

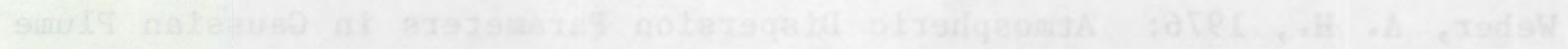

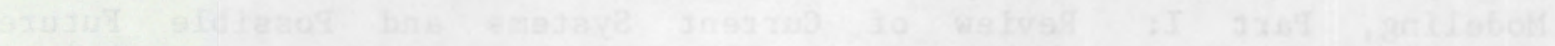

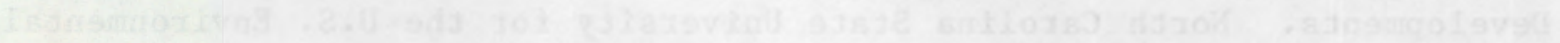

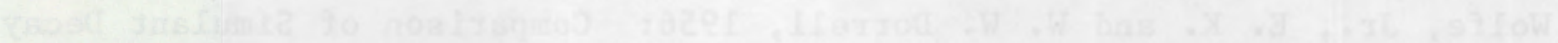

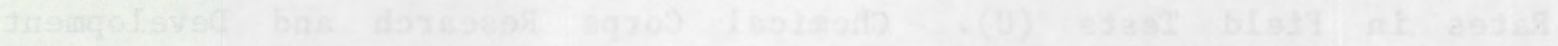

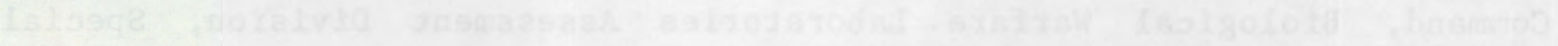

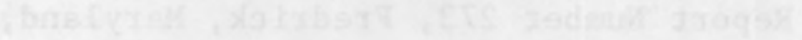




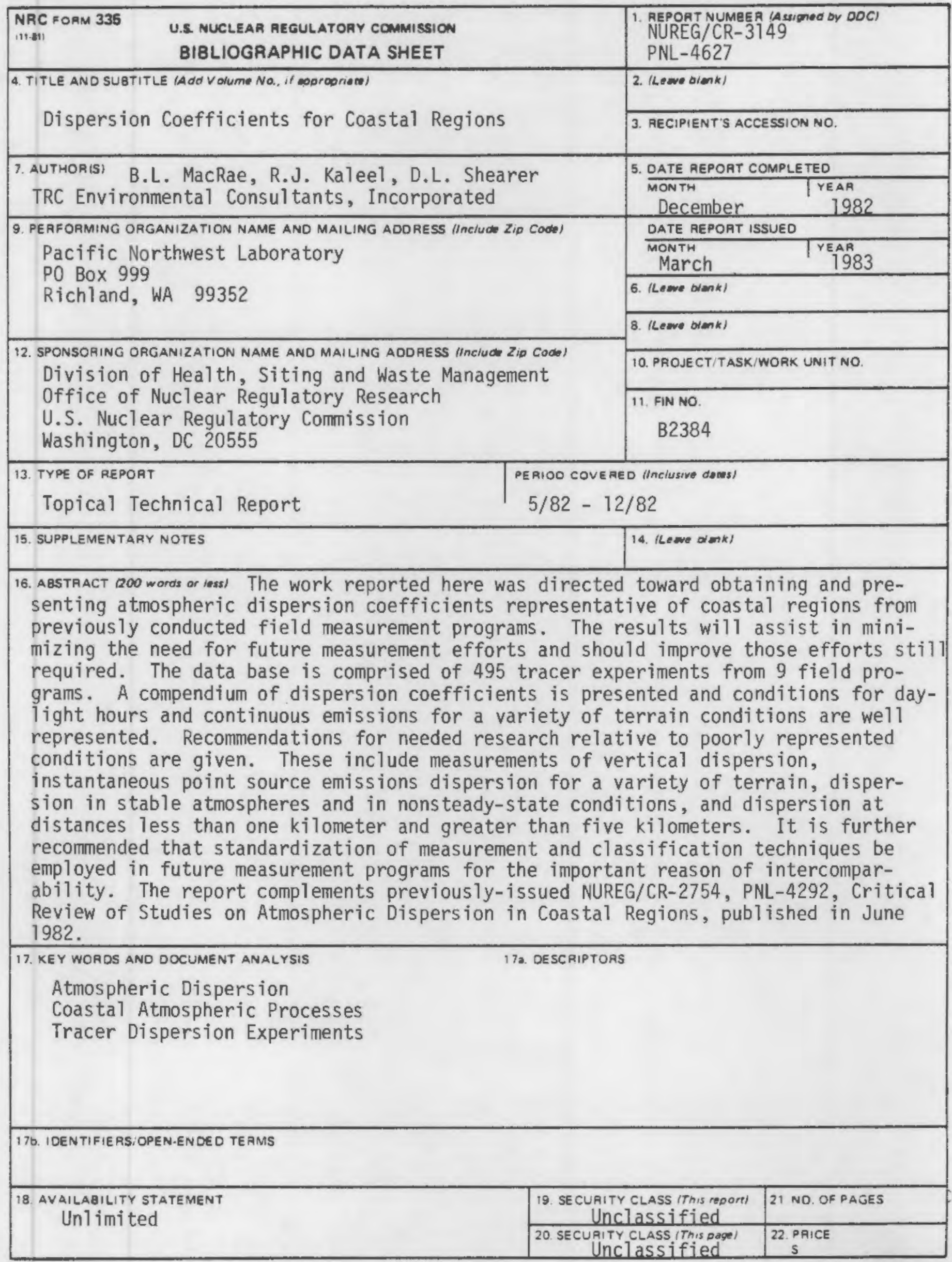




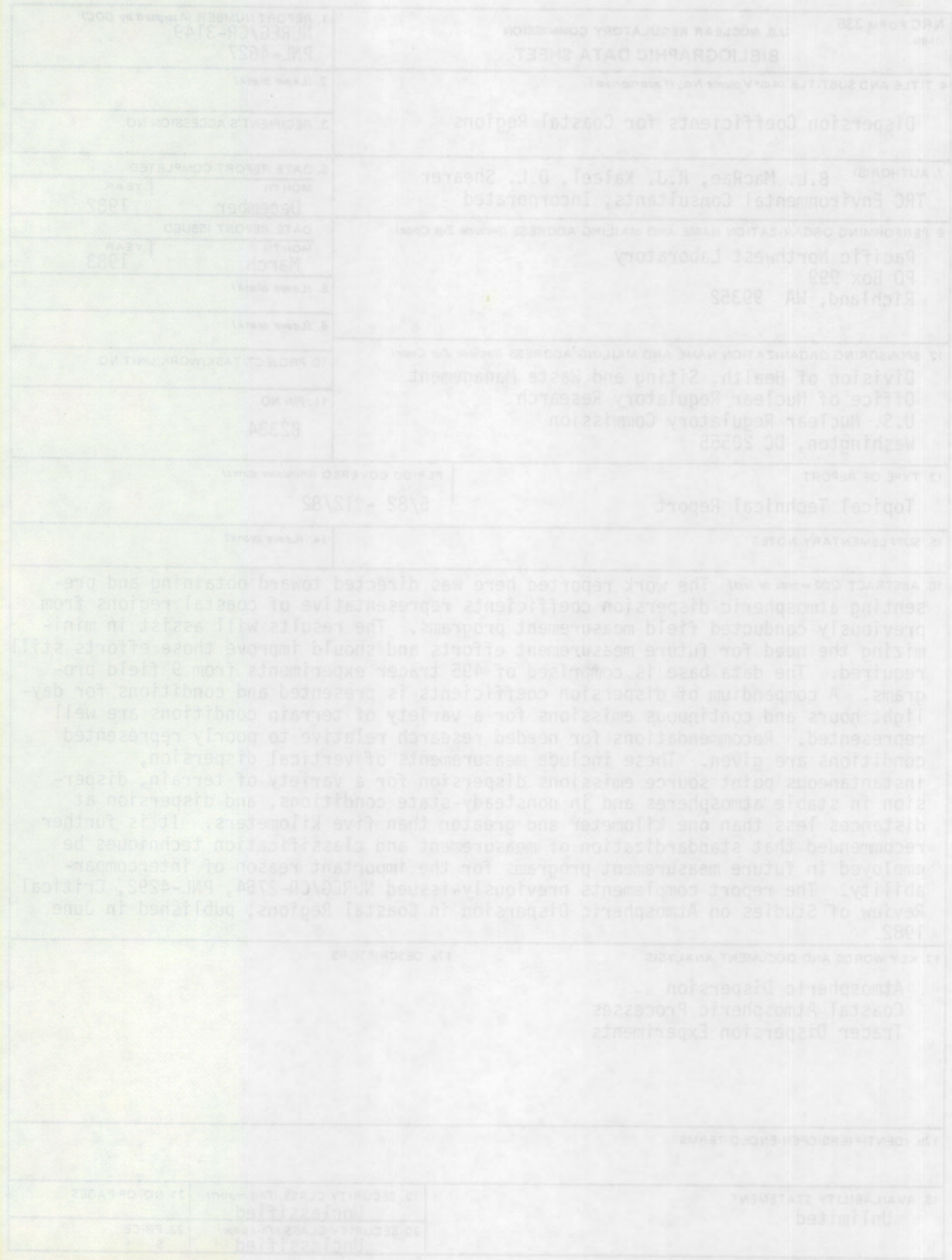

